\title{
The most complete enantiornithine from North America and a phylogenetic analysis of the Avisauridae
}

\author{
Jessie Atterholt ${ }^{\text {Corresp., }}{ }^{1,2,3}$, J. Howard Hutchison ${ }^{1}$, Jingmai K O'Connor ${ }^{4,5}$ \\ 1 Department of Integrative Biology, University of California, Berkeley, Berkeley, California, United States \\ 2 Raymond M. Alf Museum of Paleontology, Claremont, California, United States \\ 3 Graduate College of Biomedical Sciences, Western University of Health Sciences, Pomona, CA, USA \\ 4 Key Laboratory of Vertebrate Evolution, Institue of Vertebrate Paleontology and Paleoanthropology, Chinese Academy of Sciences, Beijing, People's \\ Republic of China \\ ${ }^{5}$ CAS Center for Excellence in Life and Paleoenvironment, Beijing, People's Republic of China \\ Corresponding Author: Jessie Atterholt \\ Email address: jessie.atterholt@gmail.com
}

The most complete known North American enantiornithine was collected in 1992 but never formally described. The so-called 'Kaiparowits avisaurid' remains one of the most exceptional Late Cretaceous enantiornithine fossils. We recognize this specimen as a new taxon, Mirarce eatoni (gen. et sp. nov.), and provide a complete anatomical description. We maintain that the specimen is referable to the Avisauridae, a clade previously only known in North America from isolated tarsometatarsi. Information from this specimen helps to clarify evolutionary trends within the Enantiornithes. Its large body size supports previously observed trends towards larger body mass in the Late Cretaceous. However, trends towards increased fusion of compound elements across the clade as a whole are weak compared to the Ornithuromorpha. The new specimen reveals for the first time the presence of remige papillae in the enantiornithines, indicating this feature was evolved in parallel to dromaeosaurids and derived ornithuromorphs. Although morphology of the pygostyle and (to a lesser degree) the coracoid and manus appear to remain fairly static during the 65 million years plus of enantiornithine evolution, by the end of the Mesozoic at least some enantiornithine birds had evolved several features convergent with the Neornithes including a deeply keeled sternum, a narrow furcula with a short hypocleidium, and ulnar quill knobs - all features that indicate refinement of the flight apparatus and increased aerial abilities. We conduct the first cladistic analysis to include all purported avisuarid enantiornithines, recovering an Avisauridae consisting of a dichotomy between North and South American taxa. Based on morphological observations and supported by cladistic analysis, we demonstrate Avisaurus to be paraphyletic and erect a new genus for 'A.gloriae,' Gettyia gen. nov. 
1 The most complete enantiornithine from North America and a phylogenetic analysis of the

2 Avisauridae

3

4 Jessie Atterholt ${ }^{1,2,3}$, J. Howard Hutchison ${ }^{1}$, and Jingmai O’Connor ${ }^{4,5}$

5

$6{ }^{1}$ Department of Integrative Biology, University of California, Berkeley, CA, USA

7 2Raymond M. Alf Museum of Paleontology, Claremont, CA, USA

$8{ }^{3}$ Western University of Health Sciences, Pomona, CA, USA

$9{ }^{4}$ Key Laboratory of Vertebrate Evolution and Human Origins, Institute of Vertebrate

10 Paleontology and Paleoanthropology, Chinese Academy of Sciences, Beijing, 10010, P. R. China

$11{ }^{5}$ CAS Center for Excellence in Life and Paleoenvironment, Beijing, 10010, P. R. China

12

13

14 Corresponding author:

15 Jessie Atterholt ${ }^{1,2,3}$

16

17 Email address: jessie.atterholt@gmail.com

18 
The most complete enantiornithine from North America and a phylogenetic analysis of the Avisauridae

Jessie Atterholt ${ }^{1,2,3}$, J. Howard Hutchison ${ }^{1}$, and Jingmai O’Connor ${ }^{4,5}$

24

${ }^{1}$ Department of Integrative Biology, University of California, Berkeley, CA, USA

${ }^{2}$ Raymond M. Alf Museum of Paleontology, Claremont, CA, USA

${ }^{3}$ Western University of Health Sciences, Pomona, CA, USA

${ }^{4}$ Key Laboratory of Vertebrate Evolution and Human Origins, Institute of Vertebrate

Paleontology and Paleoanthropology, Chinese Academy of Sciences, Beijing, 10010, P. R. China

${ }^{5}$ CAS Center for Excellence in Life and Paleoenvironment, Beijing, 10010, P. R. China

\section{Abstract} never formally described. The so-called 'Kaiparowits avisaurid' remains one of the most exceptional Late Cretaceous enantiornithine fossils. We recognize this specimen as a new taxon, Mirarce eatoni (gen. et sp. nov.), and provide a complete anatomical description. We maintain that the specimen is referable to the Avisauridae, a clade previously only known in North America from isolated tarsometatarsi. Information from this specimen helps to clarify evolutionary trends within the Enantiornithes. Its large body size supports previously observed trends towards larger body mass in the Late Cretaceous. However, trends towards increased fusion of compound elements across the clade as a whole are weak compared to the Ornithuromorpha. The new specimen reveals for the first time the presence of remige papillae in the enantiornithines, indicating this feature was evolved in parallel to dromaeosaurids and derived ornithuromorphs. Although morphology of the pygostyle and (to a lesser degree) the coracoid and manus appear to remain fairly static during the 65 million years plus of enantiornithine evolution, by the end of the Mesozoic at least some enantiornithine birds had evolved several features convergent with the Neornithes including a deeply keeled sternum, a narrow furcula with a short hypocleidium, and ulnar quill knobs - all features that indicate refinement of the flight apparatus and increased aerial abilities. We conduct the first cladistic 
50

51

52

53

54

55

56

57

58

analysis to include all purported avisaurid enantiornithines, recovering an Avisauridae consisting of a dichotomy between North and South American taxa. Based on morphological observations and supported by cladistic analysis, we demonstrate Avisaurus to be paraphyletic and erect a new genus for 'A. gloriae,' Gettyia gen. nov.

\section{Introduction}

The Enantiornithes are a diverse group of Cretaceous land birds first recognized by Cyril Walker (1981) from an assemblage of isolated, three-dimensionally preserved bones collected from deposits of the Maastrichtian Lecho Formation at the El Brete locality in Argentina (Chiappe 1993, Chiappe 1996, Walker and Dyke 2009). The disarticulated and isolated nature of the "El Brete" material left open the possibility that the Enantiornithes was paraphyletic (Steadman, 1983). However, through the discovery of an articulated partial skeleton later used to erect the taxon Neuquenornis volans, Chiappe (1992) demonstrated both the validity of the Enantiornithes as well as the avian affinity of an enigmatic clade, the Avisauridae. Today, the Enantiornithes are considered the first major avian radiation and the dominant clade of land birds in the Cretaceous. Their remains have been collected on every continent except Antarctica, in some cases occurring in great abundance, and by the Late Cretaceous they appear to have occupied a wide range of ecological niches including one potentially flightless form (O'Connor, Chiappe et al. 2011).

Most data regarding the Enantiornithes come from the 125-120 Ma Jehol Group where thousands of nearly complete and fully articulated specimens have been uncovered (Zhou and Zhang 2007) accounting for approximately half the currently recognized diversity. Although nearly complete, these specimens are typically two-dimensionally preserved, and elements are often split between two slabs such that fine anatomical details often cannot be discerned. In contrast, relatively few specimens have been collected from Upper Cretaceous deposits. Only four taxa are represented by partial skeletons: the holotype of Parvavis chuxiongensis (Wang, Zhou et al. 2014), the only reported Late Cretaceous bird from China; the potentially flightless Elsornis kenii from Mongolia (Chiappe, Suzuki et al. 2007); Neuquenornis volans from Argentina (Chiappe and Calvo 1994); and Nanantius valifanovi from Mongolia, here considered a junior synonym of Gobipteryx minuta (Elzanowski 1974; Kurochkin, 1986; Chiappe et al., 
81 2001). An additional taxon, "Gobipipus "(Kurochkin et al., 2013) was erected based on fairly

82 complete embryonic remains, but "Gobipipus" and other juvenile specimens (Elzanowski 1981)

83 lack diagnostic features and are not useful for comparison with the adult material studied here.

84 The remainder of the Late Cretaceous record is far more incomplete, consisting of small

85 associations of fragmentary elements and individual isolated, partial elements, many used to erect new taxa. These are primarily collected in South America but are also known from North America, Madagascar, and Eurasia (e.g., Yungavolucris brevipedalis, Soroavisaurus australis, Bauxitornis mindszentyae, Flexomornis howei, Incolornis martini) (Chiappe 1993, Dyke and Ösi 2010, O'Connor and Forster 2010, Tykoski and Fiorillo 2010, Panteleev 2018). Although a majority of Late Cretaceous taxa are based on single complete — or even fragmentary-elements, the material tends to be well preserved in three-dimensions revealing anatomical details that are rarely preserved in two-dimensional specimens from the Early Cretaceous. This makes comparison between enantiornithines early and late in their evolution difficult and hinders the study of evolutionary trajectories within the clade (O'Connor 2009).

The enantiornithine fossil record is particularly poor in North America and entirely limited to the Late Cretaceous (Fig. 1). The first probable enantiornithines from North America were collected in the 19th Century and consisted of three metatarsal fragments found in the Wyoming Lance Formation, including an incomplete metatarsal III that may be referable to $A$. archibaldi (Chiappe and Walker 2002). Since then, several more unnamed fragments have been described including RAM 14306, a partial coracoid also from the Kaiparowits Formation (Farke and Patel 2012), a distal tibiotarsus from Dinosaur National Monument (Buffetaut 2010), and several fragmentary coracoids from the Hell Creek Formation (Longrich, Tokaryk et al. 2011). Slightly more complete specimens were used to erect taxa. In Montana, two taxa were named from isolated tarsometatarsi: Avisaurus archibaldi from the Hell Creek Formation (Brett-Surman and Paul 1985) and Avisaurus gloriae from the Two Medicine Formation (Varricchio and Chiappe 1995). Alexornis antecedens from the Bocana Roja Formation in Baja California (Brodkorb 1976), Halimornis thompsoni from the Mooreville Chalk Formation of Alabama

108 (Chiappe, Lamb et al. 2002), and Flexomornis howei from the Woodbine Formation of Texas

109 (Tykoski and Fiorillo 2010) are all known from small associations of fragmentary elements. The 110 most complete of these, Halimornis, consists only of a proximal humerus, partial scapula, distal 111 femur, pygostyle, and a thoracic vertebra (Chiappe, Lamb et al. 2002). A proximal humerus from 
112 New Mexico has been referred to the genus Martinavis, which otherwise occurs in Argentina and

113 France (Walker, Buffetaut, et al. 2007). However, the first probable enantiornithines collected in

114 North America were three metatarsal fragments found in the Lance Formation in Wyoming

115 during the 19th Century, including an incomplete metatarsal III that may be referable to $A$.

116 archibaldi.

117 Originally, A. archibaldi was described as a member of a new clade of non-avian

118 theropod dinosaurs, the Avisauridae (Brett-Surman and Paul 1985). An isolated tarsometatarsus

119 belonging to the original El Brete collection described by Walker (1981) was also referred to the

120 clade (Brett-Surman \& Paul 1985) and later used to erect a new taxon, Soroavisaurus australis

121 (Chiappe 1993). With the new data provided by the discovery of Neuquenornis, Chiappe (1992)

122 provided support for the enantiornithine affinity of the Avisauridae, consisting of these three

123 taxa. Subsequently, several additional taxa have been referred to this clade (including A. gloriae

124 [Varricchio and Chiappe 1995)]), some through phylogenetic analysis (e.g., Enantiophoenix) and

125 others based only on morphological observations (e.g., Bauxitornis, Intiornis) (Cau and Arduini,

126 2008; Dyke \& Osi, 2010; Novas et al., 2010).

127 Here we describe the full anatomy of UCMP 139500, the most complete enantiornithine

128 collected in North America to date. Although originally found in 1992, it has only been

129 preliminarily described in an abstract, referring the specimen to the Avisauridae (Hutchison

130 1993). Like most other Late Cretaceous enantiornithines, UCMP 139500 is well-preserved in

131 three-dimensions and contributes substantially to our understanding of Late Cretaceous skeletal

132 anatomy as a whole, as well as with regard to the North American Avisauridae, otherwise known

133 only from isolated tarsometatarsi. The specimen was found disarticulated weathering out of a

134 clay rip-up clast in a paleo-channel deposit. We provide a complete anatomical description of the

135 'Kaiparowits avisaurid,' re-assess the validity of the Avisauridae through the first phylogenetic

136 analysis to include all purported members of the clade, and discuss the impact of UCMP 139500

137 on existing hypotheses regarding evolutionary trends within the Enantiornithes.

139 Institutional abbreviations: FMNH, Field Museum of Natural History, Chicago, Illinois; MTM,

140 Magyar Természettudományi Múzeum, Budapest, Hungary; PVL, Fundación Instituto Miguel

141 Lillo, Tucumán, Argentina; RAM, Raymond Alf Museum of Paleontology, Claremont,

142 California; UCMP, University of California Museum of Paleontology, Berkeley, California. 
Methods

145 Systematic Paleontology

146 Class AVES Linnaeus, 1758

ORNITHOTHORACES Chiappe, 1995

148

Subclass ENANTIORNITHES Walker, 1981

149

Family AVISAURIDAE Brett-Surman and Paul, 1985

150

Revised diagnosis: Enantiornithine birds with the following unique combination of

152 morphological features: tarsometatarsus with inclined proximal articular surface; strong

153 transverse convexity of the dorsal surface of the mid-shaft of metatarsal III; a distinct plantar

154 projection of the medial rim of the trochlea of metatarsal III (unambiguously supported in our

155 phylogenetic analysis); and a laterally compressed J-shaped metatarsal I (modified from Chiappe 156 [1993]).

157 Phylogenetic definition: the last common ancestor of Neuquenornis volans and Avisaurus 158 archibaldi plus all its descendants (Chiappe 1993).

159 Included genera: Avisaurus (Brett-Surman and Paul 1985); Soroavisaurus (Chiappe 1993);

160 Neuquenornis (Chiappe and Calvo 1994); Intiornis (Novas, Agnolín et al. 2010); Mirarce

161 (current study); and Gettyia (current study).

162

MIRARCE GEN. NOV.

164 Etymology: Named for its spectacular preservation and level of morphological detail (Latin

165 "mirus" for wonderful), and after Arce, winged messenger of the titans in Greek mythology, for

166 the evidence suggesting a refined flight apparatus in this species.

167

168 Diagnosis: As for the type and only known species, given below.

Type species: Mirarce eatoni sp. nov. (by monotypy)

Etymology: The type species is named in honor of Dr. Jeffrey Eaton, for his decades of work 
Holotype: UCMP 139500, a three-dimensional partial skeleton consisting of several cervical and thoracic vertebrae (including the axis), the pygostyle, almost all phalanges from the left pes and several from the right, a complete humerus, femur, and tarsometatarsus, a partial scapula, coracoid, furcula, and tibiotarsus, as well as fragments of the sternum, radius, ulna, carpometacarpus, and manual phalanges (see Table 1 for measurements of select elements).

Type horizon and locality: UCMP locality V93097, Late Cretaceous (late Campanian 76-74.1Ma [Roberts et al. 2005]) Kaiparowits Formation of Grand Staircase-Escalante National Monument in Garfield County, Utah, USA.

The electronic version of this article in Portable Document Format (PDF) will represent a published work according to the International Commission on Zoological Nomenclature (ICZN), and hence the new names contained in the electronic version are effectively published under that Code from the electronic edition alone. This published work and the nomenclatural acts it contains have been registered in ZooBank, the online registration system for the ICZN. The ZooBank LSIDs (Life Science Identifiers) can be resolved and the associated information viewed through any standard web browser by appending the LSID to the prefix http://zoobank.org/. The LSIDs for this publication are: genus name - urn:lsid:zoobank.org:act:A90E4FD8-999B-4B7DBE33-B288D10FC8E8; species name - urn:lsid:zoobank.org:act:58005BE1-E4F5-4B7C-9A0CFD94A0B80F30; publication LSID - urn:lsid:zoobank.org:pub:269CEBCA-EC05-425D-B71D1A5507C8E48B. The online version of this work is archived and available from the following digital repositories: PeerJ, PubMed Central, and CLOCKSS.

\section{Diagnosis}

A large, turkey-sized avisaurid (see above diagnosis) enantiornithine (thoracic vertebrae with centrally located parapophyses; pygostyle cranially forked with ventrolateral processes;

202 furcula dorsolaterally excavated; [Chiappe \& Walker 2002]) with the following autapomorphies: 203 posterior end of sternum weakly flexed caudodorsally, terminating in a small knob; ulnae with remige papillae present; small, deep, circular pit located just craniolateral to the femoral 
205 posterior trochanter; small, triangular muscle scar on medial margin of the femoral shaft just 206 distal to the head followed distally by a much larger proximodistally elongate oval; distinct, 207 rugose ridge-like muscle attachment located on the craniomedial margin of the femur a quarter

208 length from the distal end; and tubercle for the $m$. tibialis cranialis located at the mid-point of the 209 shaft of metatarsal II on the dorsal surface. The new species is further distinguished by the 210 unique combination of the following characters: acrocoracoidal tubercle very weakly developed

211 and medially located; furcula with truncate (untapered) omal tips weakly developed into articular

212 facets and oriented perpendicular to the axis of the rami; ventral projection of the sternal keel

213 proportionately greater than in most other enantiornithines (similar to condition observed in

214 Neuquenornis); acetabulum fully perforate; medial surface of the medial condyle of the

215 tibiotarsus with deep circular excavation; and elongate, slightly raised, flat, oval surface present

216 on the medial edge of the plantar surface of metatarsal II continuous with a weak medial plantar

217 crest.

218

219 Differential diagnosis

220 Compared to other avisaurids: metatarsals entirely unfused except for the proximal ends

221 (proximal 1/3 fused in A. archibaldi; III and IV fused distally in 'A. gloriae'); proximal articular

222 surface very weakly inclined (slightly less than in $A$. archibaldi; strongly inclined in ' $A$.

223 gloriae ); trochlea of metatarsal IV weakly lunate in plantar view (strongly lunate in $A$.

224 archibaldi); tubercle for the m. tibialis cranialis developed on the dorsomedial surface of

225 metatarsal II is more distally located than in $A$. archibaldi (slightly less distal than in ' $A$.

226 gloriae ); elongate, slightly raised, flat, oval surface on medioplantar surface of metatarsal II

227 more elongate and proximally located in $A$. archibaldi; and asymmetry of condyles in the

228 trochlea of metatarsals II and III is less developed compared to the condition in A. archibaldi.

229

230 Ontogenetic Assessment

231 Gross morphology indicates the specimen was an adult at the time of death. All preserved

232 compound elements (e.g., the distal tibiotarsus, distal carpometacarpus) are fused to the extent

233 typically observed in other enantiornithines, including the tarsometatarsus, in which the distal

234 tarsals fuse to the metatarsals relatively late in enantiornithine development (Hu and O'Connor

235 2017). Although considered an adult, size may have increased and fusion continued to progress 
236 given that protracted growth is observed in other Late Cretaceous enantiornithines (Chinsamy,

237 Chiappe et al. 1995) and that other North American avisaurids show a greater degree of fusion

238 between the metatarsals.

239

240 Description

241 Axial Skeleton

$242 \quad$ Cervical Vertebrae

243 Three cervical vertebrae are preserved, including the axis (Fig. 2 A-E). The peg-like dens

244 projects dorsal to the atlantean articular facet; its craniocaudal length is 1.5 times its mediolateral

245 width. The articular facets of the postzygapophyses are oriented ventrally with slight lateral

246 deflection and are medially continuous with each other through a thin shelf of bone that

247 overhangs the vertebral foramen. The epipophyses are strongly developed but do not extend

248 caudally beyond the caudal margin of the postzygapophyses. The caudal articular surface of the

249 axis appears weakly heterocoelic.

250 The two post-axial cranial cervical vertebrae are substantially longer than the axis

251 (approximately 1.5 times its length). The prezygapophyses are flat (epipophyses absent),

252 cranioventral-caudodorsally oriented, and sub-lachriform (tapered dorsally with a straight medial

253 margin and a convex lateral margin). A low but even neural spine extends nearly the entire

254 length of the centrum. The ventral surface of the centrum also appears to form a low keel. The

255 caudal articular surface of the vertebra is dorsoventrally concave and mediolaterally convex.

$256 \quad$ Dorsal Vertebrae

257 Two dorsal vertebrae were found; they are amphicoelous with slightly concave articular

258 surfaces that are much larger than the vertebral foramen (Fig. 2F-J). The vertebrae are spool-

259 shaped with deep grooves excavating the lateral surfaces. In one vertebra, a lateral groove

260 appears to be perforated by a foramen in the cranial portion, but this may be a preservational

261 artifact. The ventral surface is not keeled as in Elsornis and some El Brete specimens (Chiappe et

262 al., 2007). The parapophyses are centrally located, as in other enantiornithines (Chiappe \&

263 Walker, 2002). The spinous process is as dorsoventrally tall as the centrum, narrowest at its base,

264 and slightly displaced caudally (not centered on the centrum), typical of enantiornithines

265 (Chiappe \& Walker, 2002). The transverse processes are not preserved.

Pygostyle 

enantiornithines (Wang and O'Connor 2017). The proximal end bears a craniodorsal fork formed by the prezygapophyses of the first fused vertebra. In dorsal view, these processes define a deep U-shaped concavity (Fig. 3), whereas they form a V-shaped incisure in Halimornis. The cranial fork is continuous with the dorsolateral margins. The dorsal surface is gently concave and wider than the ventral surface. Ventrally the pygostyle bears a prominent pair of laminar ventrolateral processes, which extend $80 \%$ the length of the pygostyle and taper distally without the pronounced constriction present in some taxa (e.g., Halimornis, Longipteryx [Zhang et al. 2001]) or medial invagination present in the caudal margin of the pygostyle in pengornithids (Wang and O'Connor 2017).

Thoracic girdle

279

\section{Furcula}

The furcula is nearly-complete and well preserved, with only moderate mediolateral crushing (Fig. 4). It is Y-shaped with an interclavicular angle of approximately $40^{\circ}$, less than observed in many Early Cretaceous taxa (Wang, O'Connor, et al. 2014). The omal halves of the clavicular rami are subparallel, whereas they typically are more widely splayed in Early Cretaceous taxa. Although the narrow interclavicular angle in this specimen may be somewhat exaggerated by crushing, this morphology appears comparable with the South American avisaurid Neuquenornis. Another similarity between these two taxa is a short hypocleidium (though we note that this structure may be incomplete in Neuquenornis), measuring less than 1/4 the length of the clavicular rami in Mirarce, compared to half the length or more in many Early Cretaceous enantiornithines (Wang, O'Connor, et al. 2014). The omal tips of the furcular rami are weakly expanded before they abruptly truncate. The omal margin is concave, presumably forming a facet for articulation with the coracoid, and oriented perpendicular to the long axis of 292 the rami.

Only the xiphoid process of the sternum was recovered (Fig. 5). The lateral margins are straight in dorsal and ventral view as in most enantiornithines, whereas the xiphial margin

296 demarcates a wide V-shape (xiphoid process absent) in primitive enantiornithines (e.g., 297 Protopteryx, Pengornithidae)(Hu, Zhou, et al., 2014). The dorsal surface is weakly concave. 
298 Ventrally, the narrow process bears a well-developed keel, similar to that in preserved in

299 Neuquenornis, that decreases in height caudally. In contrast, the keel of Elsornis and Early

300 Cretaceous enantiornithines is poorly developed along the xiphoid process (O'Connor 2009).

301 The posterior end is weakly flexed caudodorsally and terminates in a small knob not observed in

302 other enantiornithines.

$303 \quad \underline{\text { Scapula }}$

304 The shaft of the left scapula is present, but the proximal and the caudal extremities are

305 not preserved (Fig. 6). The scapular blade is straight in mediolateral view. The cranial half of the

306 costal surface is excavated by a shallow fossa defined by a thickening of the dorsal margin of the

307 blade, a morphology also observed in Elsornis, Halimornis, and Neuquenornis (Chiappe et al.,

308 2002, 2006; Chiappe and Calvo, 1992). The caudal half of the lateral surface is also excavated by

309 a shallow, elongate fossa, as in Halimornis. Although obfuscated by breakage, the preserved

310 portion of the scapular blade weakly tapers distally.

$311 \quad$ Coracoid

312 The omal half and sternal margin of the left coracoid are preserved as separate fragments.

313 As in other enantiornithines the acrocoracoid, glenoid, and scapular cotyla are proximodistally

314 aligned in dorsal view (Chiappe and Walker, 2002) (Fig. 7). The acrocoracoid is straight and

315 rounded, typical of most enantiornithines (Chiappe and Walker, 2002; Panteleev, 2018), whereas

316 this process is medially hooked in pengornithids (Hu, Zhou, et al., 2014). The acrocoracoidal

317 tubercle is weakly developed and blunt, in contrast to the angular tubercle observed in

318 Enantiornis leali (Walker 1981) and RAM14306 (Farke and Patel 2012). In medial view a

319 groove partially separates the weakly convex scapular cotyla from the glenoid, just distal to the

320 tubercle; this feature is more strongly developed in RAM 14306. The neck is perforated medially

321 by a supracoracoidal nerve foramen as in some enantiornithines (Chiappe and Walker 2002;

322 Panteleev 2018) (Fig. 7). The dorsal surface of the neck is weakly concave; this becomes a large

323 fossa distal to the supracoracoidal nerve foramen. Similar well-developed dorsal fossae are

324 present in a number of Late Cretaceous enantiornithines (Chiappe and Walker 2002; Panteleev

325 2018). The sternal margin lacks a lateral process, as in other enantiornithines. The medial angle

326 is acute, the lateral angle is caudally directed, and the sternal margin is concave, as in

327 Enantiornis and Elsornis. The sternal margin is thickest along the medial portion, and the corpus

328 narrows laterally, as in many other enantiornithines (Wang et al., 2015a). Although difficult to 
329 determine unequivocally because the element is incomplete, it appears the sternal margin was not

330 angled caudolaterally, as in some Late Cretaceous enantiornithines (Buffetaut 1998).

331

332 Thoracic limb

333 Humerus

334 The humerus is fairly short and robust. The proximal end is typically enantiornithine in

335 profile: concave centrally rising dorsally and ventrally (whereas it is straight to convex in the

336 basal Pengornithidae)(Chiappe \& Walker, 2002; Hu et al., 2015; Zelenkov, 2017) (Fig. 8). The

337 cranial surface of the humerus is deeply concave, a shape exaggerated by the presence of a

338 centrally located circular fossa which is also present in most other Late Cretaceous

339 enantiornithines (e.g. Enantiornis [Chiappe 1996], Gurilynia [Kurochkin 1999], Martinavis

340 [Walker et al. 2007]), and which may represent the coracobrachial impression (O'Connor 2009).

341 The deltopectoral crest is 0.4 times the length of the humerus, proportionately longer than in

342 other Late Cretaceous taxa, and is nearly half the width of the shaft. The distal end truncates

343 rapidly such that the crest is rectangular, typical of enantiornithines (O'Connor 2009). The

344 cranioventral surface of the bicipital crest is deeply excavated by a pit possibly for the $m$.

345 scapulohumeralis caudalis (Chiappe and Walker 2002). Similar to Halimornis, the enlarged,

346 ridge-like ventral tubercle is separated by a deep capital incision, which wraps around to the

347 proximal articular surface of the humerus and is continuous with the bicipital crest (Chiappe et

348 al., 2002). As in other Late Cretaceous enantiornithines the ventral tubercle is excavated by a

349 pneumotricipital fossa (this is perforated only in PVL 4022 [Chiappe and Walker 2002]). A

350 second pneumatic fossa is continuous with the capital incision just distal to the proximal articular

351 surface.

352 The humeral shaft is bowed. The distal end is craniocaudally compressed and

353 mediolaterally expanded, as in other Late Cretaceous enantiornithines (e.g. Martinavis,

354 Enantiornis)(Chiappe 1996; Chiappe and Walker 2002). The condyles are slightly staggered

355 such that the dorsal condyle is proximal to the ventral condyle and a deep intercondylar incisure

356 cuts between them. This incisure is weakly angled proximoventral-distodorsally and is parallel to

357 the long axis of the dorsal condyle. The ventral condyle is transversely oriented, as in other

358 enantiornithines (Chiappe and Walker 2002). A large flexor process is present, projecting distally

359 such that the distal margin is angled as in some other enantiornithines (e.g. Alexornis)(Chiappe 
360 and Walker 2002). The olecranon fossa is present only as a shallow incision between the flexor

361 process and condyles. Tricipital grooves are absent.

$362 \quad \underline{\text { Ulna }}$

363 The right ulna is preserved as a mineral cast of the endosteal cavity with only small

364 fragments of cortex present. Together, these indicate that the bone was slightly bowed, as in

365 other enantiornithines and most basal birds. Distally, the semilunate ridge (external condylar

366 ridge) is strongly developed. Two rugose patches preserved on the caudal margin of the shaft are

367 interpreted as quill knobs (remige papillae) (Fig. 9). These prominent rugosities are elongated in

368 parallel to the long axis of the bone. Although breakage of the fossil makes it impossible to

369 determine the length of each papilla, to measure the spacing between them, or to estimate the

370 number of secondary feathers, recognition of these structures for the first time in an

371 enantiornithine is highly significant.

372 The quill knobs in Mirarce are much more substantial than those reported in non-avian

373 theropods (e.g., Velociraptor [Turner et al. 2007], Concavenator [Ortega et al. 2010]), bearing a

374 closer similarity to quill knobs seen in modern birds (Edington and Miller 1942, Hieronymus

375 2015). Morphology of remige papillae varies among extant birds to the extent that Livezey and

376 Zusi (2007) use four states to characterize this feature in their comprehensive phylogenetic

377 analysis of living birds. Quill knobs, when present, range from small impressions to prominent

378 tuberculae. In some taxa with very prominent papillae, they vary from distinct, separate knobs

379 (e.g., Platalea leucorodia, Tadorna ferruginea [Edington \& Miller 1942]) to more elongate

380 tumescences that are connected along a thin, continuous ridge (e.g., Sagittarius serpentarius,

381 Antigone antigone, Neophron percnopterus [Edington \& Miller 1942]). The quill knobs of

382 Mirarce appear most similar to these latter taxa but are flatter and wider than observed in modern

383 birds.

384

$\underline{\text { Radius }}$

385

Proximal and distal ends of a right radius are preserved, along with fragments of the shaft

386 that indicate that an interosseous groove, like that observed in some other enantiornithines (e.g. Enantiornis) was absent (Chiappe and Walker 2002). Proximally the circular humeral cotyla is concave. The distal fragment of the right radius preserves the radiocarpal and ulnar articular surfaces oriented at a $90^{\circ}$ angle and separated by a small, distally-projecting tubercle. The 
390 radiocarpal articular face is visible, forming a bluntly triangular facet on the dorsal surface of the

391 radius; it covers the entire distal margin and even has a small extension on the ventral surface.

$392 \quad$ Carpometacarpus

393 A small fragment is identified as the carpal trochlea of the right carpometacarpus reveals

394 asymmetry in the carpal trochlea, as in some living birds (e.g., Phalacrocorax, Lagopus, Gallus),

395 with the dorsal condyle projecting farther (Fig. 10A-D). The fragment strongly suggests the

396 carpometacarpus was fully fused at the proximal end, as in all adult enantiornithines. Another

397 fragment is interpreted as the distal end of metatarsal II; the distal articular surface for the first

398 phalanx is heart shaped. This fragment shows no signs of even partial fusion to the minor

399 metacarpal, as in Neuquenornis and all other known enantiornithines (Chiappe and Walker

400 2002).

401

402

403

The cranial margin is flat and wide, and the caudal margin is keeled forming a triangular cross

404

section. As in other enantiornithines, the phalanx lacks the caudal expansion and dorsoventral

405

compression that is present in ornithuromorphs (O’Connor, Chiappe, et al. 2011). Breakages

406

reveal large, pneumatic chambers in interior of the phalanx.

407

408

Pelvic Girdle

409

Only the fused portions of the pelvic elements contributing to the left acetabulum were

410 recovered (Fig. 11). The antitrochanter is small, triangular, and laterally oriented. It is positioned

411 on the caudodorsal margin of the acetabulum as in other enantiornithines (Chiappe and Walker

412 2002). The preserved portion of the ilium indicates a dorsal antitrochanter was present along the

413 dorsal margin forming a tubercle-like expansion of the laterodorsal iliac crest located just over

414 the antitrochanter, as in some other enantiornithines (e.g. Sinornis [Sereno \& Rao 1992],

415 PVL4042 [Chiappe and Walker 2002]). Only the ventral half of the proximal pubis is present; at

416 least along this portion, the pubic shaft was not mediolaterally compressed. The large, circular

417 acetabulum appears to be fully perforated, whereas it is partially occluded in the Early

418 Cretaceous Qiliania graffini (Ji, Atterholt et al. 2011).

419

420

Pelvic Limb 

end. The femur is long, almost equal to the humerus in length and nearly twice the length of the

425

426

427 tarsometatarsus. The femoral shaft is bowed cranially, as in most Early Cretaceous enantiornithines and Martinavis; this curvature is more pronounced in the distal half of the element, as in Martinavis (Chiappe and Walker 2002; Walker and Dyke 2010). The femoral neck is relatively distinct and elongate, similar to other Late Cretaceous enantiornithines (e.g. Martinavis), and projects slightly dorsally at a proximomedial angle (wherease it projects laterally in PVL 4037 [Chiappe and Walker 2002]). A fossa for the capital ligament is not present on the femoral head (though present in femora from El Brete, e.g., PVL 4060, PVL 4037), but there is a distinct flattening and rugosity where the ligament would have presumably attached. The trochanteric crest is robust and thick, although it thins caudally. It projects proximally slightly less than the femoral head and is angled craniolaterally - caudomedially. On the cranial surface, it is laterally angled to form the craniolateral margin of the femur; as it diminishes along this surface, it becomes continuous with an intermuscular line (potentially of the mm. femorotibialis lateralis and femorotibialis intermedius)(Baumel, King, et al. 1993). This line angles medially and extends midway down the bone before splitting near the center of the cranial surface and diminishing away a quarter length from the distal margin. In two Hungarian enantiornithine femora (MTM PAL 2011.20, -.21 [Ösi 2008]) this intermuscular line is not split. The lateral surface of the femur is excavated caudolaterally by a deep posterior trochanter, as in other enantiornithines. Inside the excavation lies a delicate, cranially convex, semilunate muscle scar. The excavation of the posterior trochanter forms a laterally oriented boney shelf, as in other enantiornithines. This shelf formed by the posterior trochanter is craniocaudally convex (similar to PVL-4060) and opens on the caudal surface (Chiappe and Walker 2002). A unique feature present on both femora is a small, deep, circular pit located just craniolateral to the posterior trochanter (Fig. 12C). This may represent the point of insertion for major hip flexors, such as the mm. iliotrochantericus cranialis and medius (Mosto, Carril et al. 2013).

The medial margin of the shaft just distal to the head bears a small, triangular muscle scar followed distally by a much larger proximodistally elongate oval not observed in any other known enantiornithine (Fig. 12). In modern birds, the $m$. femorotibialis medialis has an elongate 
452 point of origin along the medial surface of the femur (Mosto, Carril et al. 2013). The more 453 prominent muscle scar present in Mirarce may possibly be analogous, suggesting a short and 454 wide origin for the $m$. femorotibialis medialis.

455 In caudal view, three distinct intermuscular lines are present (Fig. 12B). The first 456 originates on the medial surface near the proximal end of the large muscle scar, curving around 457 to the caudal surface at an angle, ending in a large oval rugosity (forming the more proximal 458 rugosity). Just distal to this landmark, another intermuscular line runs parallel to the long axis of 459 the femoral shaft, almost on the caudomedial margin of the shaft; distally it is truncated by a 460 distinct, rugose, ridge-like muscle attachment located a quarter length from the distal end 461 (forming the more distal rugosity). The third line, located on the caudolateral margin of the bone, 462 extends from the posterior trochanter distally. Near its distal end, this intermuscular line is 463 interrupted by a small, raised, lachriform muscle scar, possibly the lateral gastrocnemial tubercle 464 (Baumel et al. 1993). A fourth, faint intermuscular line parallels the middle section of the laterocaudal muscular line; these two intermuscular lines define a thick strip of rugose bone that extends from the proximal rugosity to the distal rugosity, likely representing a major site of muscle attachment. A lateral intermuscular line is also reported in an indeterminant enantiornithine from the Late Cretaceous of Madagascar (FMNH PA 752 [O'Connor \& Forster 2010]) and MTM V.2002.05 from Hungary, although in these specimens the lines do not terminate in a scar for muscle attachment.

Distally, the region between the condyles has been moderately crushed, but an intercondylar sulcus does not appear to have extended onto the cranial surface of the femur. On 473 the caudal surface, a shallow popliteal fossa is present. A weak circular impression possibly for 474 the origin of the cranial cruciate ligament is observed between the two condyles (Baumel, 1993). 475 The medial condyle is much larger than the lateral condyle, as in living birds and other enantiornithines (Chiappe and Walker 2002). The medial condyle is broad, rounded, and tapered medially, while the lateral condyle is more ridge-like and mediolaterally compressed. A prominent lateral epicondyle is present, as well as a small impression for the attachment of the collateral ligament, but the fibular trochlea is poorly developed as in other enantiornithines

480 (O'Connor 2009). A caudally-projecting lateral flange like that present in some enantiornithines 481 (e.g., Enantiornis, Neuquenornis, Concornis)(Chiappe and Walker 2002) is also absent, although 482 the lateral condyle does project further caudally and distally relative to the medial condyle. The 
483 medial surface of the medial condyle bears a deep circular excavation also present in Martinavis 484 (PVL 4036).

Tibiotarsus

Only the proximal and distal ends of the right tibiotarsus were recovered (Fig. 13). The proximal articular surface is weakly convex with a low tubercle developed in one area, similar to observations of Soroavisaurus (Chiappe 1993). Distally the medial condyle is much larger than the lateral condyle, following the plesiomorphic state for enantiornithines (Chiappe and Walker 2002). As in other enantiornithines, the two condyles contact, whereas they are separated by an intercondylar incisure in most ornithuromorphs. The medial and lateral surfaces of the condyles are both excavated by a deep circular pit present in some other well-preserved enantiornithines (e.g., Qiliania [Ji, Atterholt, et al. 2011)]). On the lateral side, the pit is closed caudodorsally by a small tubercle, similar to PVL 4021, 4027 (Chiappe and Walker 2002).

The left tarsometatarsus is complete (Fig. 14); the right tarsometatarsus is missing the distal portion. The tarsometatarsus is proportionately short and wide, similar to other avisaurids (Fig. 15). The proximal and distal ends of the metatarsals are approximately the same width, and show no distal expansion, as in Yungavolucris brevipedalis, or distal narrowing, as in Lectavis bretincola (Chiappe 1993). The metatarsals are proximally fused to the distal tarsals and to each other but are otherwise unfused throughout their lengths. In proximal view, the slightly concave medial cotyla is much wider than the flatter lateral cotyla, consistent with the widths of the tibiotarsal condyles. The two cotylae are separated by a weak convexity that continues onto the surface of the lateral cotyle - like other enantiornithines an intercotylar eminence is absent. The entire proximal articular surface is weakly angled, similar to $A$. archibaldi but lacking the extreme tilt observed in 'A. gloriae' (Fig. 15). The proximal articular surface is expanded to form a circumferential labum that overhangs the shaft of the tarsometatarsus. The labum is thickest on the plantar surface in the location of the neornithine hypotarsus, similar to the condition in basal ornithuromorphs. The plantar surface of the labum may represent the origin of the m. extensor hallucis longus, or may have supported a cartilaginous hypotarsus (Jiang, Zhao et al. 2017). The

511 proximocranial margin of the medial cotyla slopes mediodistally. The center of the

512 proximocaudal margin is slightly concave, also as in A. archibaldi, and bears a small, dorsally-

513 directed tubercle level with the intercotylar contact. In proximal view, the lateral cotyle tapers 
514 laterally and bears a minute, proximally-directed tubercle on the lateral margin, again also

515 present in $A$. archibaldi.

516 As in most other enantiornithines, the metatarsals are aligned in a single dorsoplantar

517 plane (Fig. 14). Metatarsals II and IV are straight throughout their lengths as in $A$. archibaldi, but

518 differing from the more curved metatarsals of 'A. gloriae'. No vascular foramina are observed.

519 As in other avisaurids, metatarsals II-IV are subequal in width; metatarsal IV is only marginally

520 thinner than metatarsals II and III in dorsal view, although it is much more delicate in lateral

521 view where a dorsoplantar compression is observable (especially at the midshaft). The long axis

522 of the cross-section is dorsomedial-lateroplantarly oriented such that the lateral margin of

523 metatarsal IV forms a weak plantar crest, laterally defining the excavated plantar surface of the

524 tarsometatarsus. The dorsal surface of metatarsal III is strongly convex, as in other avisaurids;

525 the dorsal surfaces of metatarsals II and IV are nearly flat. The well-developed tubercle for

526 attachment of the m. tibialis cranialis on metatarsal II is located nearly at the mid-point of the

527 element, intermediate between the position in A. archibaldi and 'A. gloriae'. As in all avisaurids,

528 the tubercle is located on the dorsomedial margin of metatarsal II, whereas it is more laterally

529 located in some enantiornithines and most ornithuromorphs (O’Connor 2009). An elongate,

530 slightly raised, flat, oval surface is present on the medial edge of the plantar surface of metatarsal

531 II, continuous with a weak medial plantar crest; a similar feature is present is present in the

532 holotype of $A$. archibaldi, but in this taxon is more elongate and proximally located. This feature

533 probably represents the attachment site of a muscle, such as the $\mathrm{m}$. abductor digiti II that

534 originates on this region of metatarsal II in modern birds (Venden Berge and Zweers 1993), or a

535 strong ligament, such as the medial plantar ligament of the tarsometatarsus, which also occupies

536 a similar position in modern taxa. This surface may alternatively represent the articular surface

537 for metatarsal I, which is not demarcated in other enantiornithines (O’Connor 2009). However,

538 in other avisaurids (Nequenornis and Soroavisaurus) metatarsal I articulates on the medial

539 surface of metatarsal II, and no enantiornithine preserves a distinct surface on metatarsal II to

540 indicate the articulation with metatarsal I. This fossa in living birds is slightly concave whereas

541 the facet in A. archibaldi and UCMP 139500 is flat. The length of the oval facet is also

542 inconsistent with its identification as the metatarsal I fossa; metatarsal I is proportionately shorter

543 in most enantiornithines (except the basal Pengornithidae). A similar scar is also present in some

544 dromaeosaurids; although early interpretations considered this to be the metatarsal I fossa, this 
545 feature has since been reinterpreted as the possible origin of the digits I and II flexor and

546 abductor tendons (Norell, Makovicky et al. 1999). Therefore, we favor interpretation of this facet

547 as the attachment point of a ligament potentially associated with the hallucal joint.

$548 \quad$ A deep and narrow medial intertrochlear incisure extends the distal third of the

549 tarsometatarsus, along with a much smaller lateral intertrochlear incisure (Fig. 14). In distal

550 view, the metatarsal trochleae are nearly coplanar, with II and IV slightly angled towards

551 metatarsal III. The distal end of metatarsal II is slightly deflected and expanded medially as in $A$.

552 archibaldi and 'A. gloriae'. The trochlea of metatarsal II is ginglymous; there is no collateral

553 ligament fovea on the medial surface of the trochlea, although there is a slight tubercle in this

554 region where the ligament could have inserted. This fovea is well developed on the lateral

555 surface of the metatarsal II trochlea and the lateral and medial surfaces of metatarsal III, and

556 weakly developed on the lateral surface of metatarsal IV (is absent in A. archibaldi). The

557 trochlea of metatarsal II is subequal in width to that of metatarsal III but the distal margin is

558 slightly angled such that the distal margin of the medial condyle is proximal to the lateral

559 condyle. The trochlea of metatarsal III is ginglymous; the dorsal surface bears a small, pit-like

560 dorsal trochlear depression continuous with an intercondylar sulcus, a morphology not developed

561 in A. archibaldi. In dorsal view, the medial condyle is slightly larger than the lateral condyle. In

562 distal view, the medial condyle projects farther plantarly and is $86 \%$ the thickness of the lateral

563 condyle. In comparison, the medial condyle is $73 \%$ the thickness of the lateral condyle in $A$.

564 archibaldi. In plantar view the medial condyle tapers sharply and extends proximally farther than

565 the lateral condyle. The trochlea of metatarsal IV is reduced to a single condyle as in other

566 enantiornithines (O’Connor, Averianov, et al. 2014); in dorsal view, the proximomedial margin

567 of the trochlea bears a very small, medially-directed tubercle that suggests an enclosed vascular

568 foramen was present between metatarsals III and IV. This indicates that the metatarsals are

569 slightly disarticulated, and that the intertrochlear incisures may be exaggerated.

$570 \quad$ Pedal Phalanges

571 A number of isolated phalanges are preserved representing parts of both the left and right

572 feet; 23 of the 28 pedal phalanges were collected, including nearly the entire left foot (Figs. 16 \&

573 17). The hallucal claw is the largest in the foot. The second digit has two phalanges that are

574 subequal in length although the second is more delicate, followed by a large claw. The first

575 phalanx of the third digit is the longest in the foot; the following two phalanges decrease in 
576 slightly in length, followed by a claw. The phalanges of the fourth digit are all short and robust

577 with a small claw that appears to be more recurved than that of the other digits; the first phalanx

578 of this digit is slightly longer than the phalanges distal to it. All non-ungual phalanges have well

579 developed medial and lateral fovea for the attachment of the collateral ligaments. All ungual

580 phalanges have a deep neurovascular groove.

581

582 Phylogenetic Analysis

583 In order to test existing hypotheses regarding the phylogenetic affinity of potential

584 avisaurid taxa, we created the first data matrix to include all such taxa: the Kaiparowits

585 specimen, A. archibaldi, 'A. gloriae', Soroavisaurus, Neuquenornis, Intiornis, Bauxitornis,

586 Concornis, Mystiornis, Halimornis, Gobipteryx, and Enantiophoenix (Elzanowski 1976, Brett-

587 Surman and Paul 1985, Sanz and Buscalioni 1992, Chiappe 1993, Chiappe and Calvo 1994,

588 Varricchio and Chiappe 1995, Chiappe, Lamb et al. 2002, Cau and Arduini 2008, Dyke and Ösi

589 2010, Novas, Agnolín et al. 2010, Kurochkin, Zelenkov et al. 2011). The new analysis is based

590 on the O'Connor and Zhou (2013) matrix, modified to include an additional state in character

591233 and seven additional tarsometatarsal characters mostly derived from previous avisaurid

592 analyses (see Supplemental Information)(Chiappe 1993, O'Connor 2009, O'Connor, Averianov

593 et al. 2014). We also included revised cranial scorings for Ichthyornis based on recently

594 published data (Field et al., 2018). The modified matrix consists of 43 taxa (26 enantiornithines,

595 ten ornithuromorphs) scored across 252 morphological characters, which we analyzed using

596 TNT (Goloboff et al., 2008a). Early avian evolution is extremely homoplastic (O'Connor,

597 Chiappe, et al. 2011, Xu 2018) thus we utilized implied weighting (without implied weights

598 Pygostylia was resolved as a polytomy due to the placement of Mystiornis) (Goloboff et al.,

599 2008b); we explored k values from one to 25 (see Supplemental Information) and found that the

600 tree stabilized at $\mathrm{k}$ values higher than 12. In the presented analysis we conducted a heuristic

601 search using tree-bisection reconnection (TBR) retaining the single shortest tree from every

6021,000 replications with a $\mathrm{k}$ value of 13 . This produced six most parsimonious trees with a score

603 of 25.1. These trees differed only in the relative placement of five enantiornithines closely

604 related to the Avisauridae, forming a polytomy with this clade in the strict consensus tree

605 (Consistency Index $=0.453$; Retention Index $=0.650$; Fig. 18). 
Enantiornithes is resolved as the sister group to the Ornithuromorpha and Sapeornis is

607

608

609

610

611

612

613

614

615

616

617

618

619

620

621

\section{Discussion}

623

624

625

626

627

628

629

630

631

632

633

634

635

636

resolved as the sister taxon to Ornithothoraces. Ichthyornis, Hesperornis, Apsaravis, and Gansus form successive out groups to Neornithes. These taxa form a dichotomy with a clade formed by Yanornis + Longicrusavis; Patagoptyeryx and Archaeorhynchus form successive outgroups, as the basal-most ornithuromorphs. These results are consistent with previous analyses (O'Connor and Zhou 2013, Wang et al. 2014, Hu and O'Connor 2017). Iberomesornis + Protopteryx are resolved in a clade as the most basal enantiornithines. The Pengornithidae (Eopengornis + Pengornis) is the outgroup to a polytomy that includes Shanweiniao, Longipteryx, Longirostravis + Rapaxavis, and all more derived enantiornithines, which includes a well resolved Avisauridae. The Avisauridae consists of a dichotomy between two clades, one formed by the Kaiparowits specimen + 'A. gloriae' and A. archibaldi and the other by Neuquenornis + Intiornis and Soroavisaurus. Avisauridae forms a polytomy with Enantiophoenix, Elsornis, Eoenantiornis, Halimornis, and Mystiornis (the taxa whose positions varied in equal length trees). Shenqiornis + Eocathayornis, a clade formed by Cathayornis + Concornis and Eoalulavis, and Bauxitornis + Gobipteryx form successive outgroups to this polytomy (Fig. 18).

First briefly mentioned in a published abstract over twenty years ago (Hutchison 1993), UCMP139500 - the 'Kaiparowits avisaurid' — remains the most complete known North American enantiornithine (Figs. 19 \& 20). UCMP139500 was originally described as a member of the Avisauridae, the first recognized clade of enantiornithines (Brett-Surman and Paul 1985) and only identified Late Cretaceous clade. This group was originally recognized based on isolated tarsometatarsi from North (A. archibaldi) and South America (Soroavisaurus) but soon after a partial skeleton representing a new species, Neuquenornis volans (Chiappe and Calvo 1994) was also referred to the clade and the first phylogenetic definition was proposed (Chiappe 1992). The clade is defined as "the common ancestor of Neuquenornis volans and Avisaurus archibaldi plus all its descendants" and diagnosed by a strong plantar projection of the medial condyle of the metatarsal III trochlea, metatarsal III midshaft cranial surface strongly convex cranial, and a J-shaped metatarsal I (Chiappe 1992). Although alternative phylogenetic definitions have been proposed (Cau and Arduini 2008) the results of this study support the original definitions provided by Chiappe (1992, 1993). 
There has been longstanding phylogenetic support for an avisaurid clade consisting of

638 Avisaurus, Soroavisaurus, and Neuquenornis (Chiappe 1993, Sanz, Chiappe et al. 1995).

639 However, since the discovery of numerous complete taxa in China, recent phylogenetic analyses

640 targeting Mesozoic birds as a whole typically have not included fragmentary taxa such as

641 Avisaurus and Soroavisaurus. A few of these analyses have included the more complete

642 Neuquenornis with Gobipteryx (Zhou and Zhang 2006, Zhou, Zhang et al. 2009, Hu and

643 O'Connor 2017). Cau et al. (2008) considered the Avisauridae to also include Enantiophoenix,

644 Concornis, and Halimornis, but not Gobipteryx. This suggested that the Avisauridae was present

645 in the Early Cretaceous and not limited to New World deposits. In the most extensive analysis of

646 enantiornithine relationships to date, all potential avisaurids with the exception of Gobipteryx

647 formed part of a large polytomy of derived taxa (O'Connor 2009). More recently, Intiornis and

648 Bauxitornis, both represented by tarsometatarsi, were also referred to the Avisauridae, but these

649 assignments were not supported through cladistic analysis (Dyke and Ösi 2010, Novas, Agnolín

650 et al. 2010). Mystiornis, known only from an isolated tarsometatarsus, preserves some avisaurid-

651 like features (such as a dorsally convex metatarsal III) and has been resolved in a clade with

652 Avisaurus outside the Enantiornithes (Kurochkin, Zelenkov et al. 2011). However, this specimen

653 was not referred to the Avisauridae because of the metatarsals are fully co-ossified, a feature not

654 present in any known enantiornithine (Kurochkin, Zelenkov et al. 2011). Fusion is heavily

655 affected by ontogeny, and we suggest that this conclusion is not strongly justified, especially in

656 light of the variable amount of fusion apparent in the tarsometatarsus of other avisaurids. A

657 previous analysis attempting to explore the phylogenetic affinity of Mystiornis with regard to the

658 Avisauridae produced a massive polytomy (O'Connor, Averianov et al. 2014).

659 Mirarce is readily identified as an avisaurid, but in order to resolve existing taxonomic

660 issues within the Avisauridae we created the first data matrix to include all potential avisaurid

661 taxa (Mirarce, A. archibaldi, 'A. gloriae', Soroavisaurus, Neuquenornis, Intiornis, Bauxitornis,

662 Concornis, Mystiornis, Halimornis, Gobipteryx and Enantiophoenix) using a version of the

663 O'Connor and Zhou (2013) matrix modified to include seven tarsometatarsal characters designed

664 to target avisaurid relationships (Fig. 18). The results support a monophyletic New World

665 Avisauridae restricted to the Late Cretaceous. Avisauridae consists of a dichotomy between

666 North (Mirarce + 'A. gloriae' and A. archibaldi) and South American taxa (Neuquenornis +

667 Intiornis and Soroavisaurus) and provides the first phylogenetic support for the inclusion of 
668 Intiornis in the Avisauridae. This clade is supported by a single unambiguous synapomorphy: 669 metatarsal III trochlea with plantarly projecting medial condyle (249:1) (see Supplemental 670 Information for complete list of synapomorphies). The dichotomy between North and South 671 American taxa is notable but expected. The South American clade is characterized by the 672 midline tapering of the tibiotarsus condyles (217:0) and the presence of a proximal vascular 673 foramen (226:1). North American avisaurids share the presence of a hypertrophied tubercle for 674 the $\mathrm{m}$. tibialis cranialis (248:1) and a medially excavated metatarsal IV trochlea (252:2). Notably, 675 both North and South American lineages include large and small bodied taxa. UCMP 139500 is 676 resolved as more closely related to 'A. gloriae' than to $A$. archibaldi, a relationship supported by 677 the shared absence of a plantarly excavated tarsometatarsus and a tubercle for the $m$. tibialis 678 cranialis that is located near the midpoint. These results indicate 'A. gloriae' should not be 679 assigned to Avisaurus. This is strongly supported by major morphological differences among 680 these three specimens (see below). Thus, we erect a new genus for 'Avisaurus' gloriae, Gettyia 681 gen. nov.

Consistent with previously observed similarities with avisaurids, Mystiornis (Kurochkin, 683 Zelenkov et al. 2011) and Enantiophoenix (Cau et al., 2008) form part of a polytomy with the 684 Avisauridae, also including Late Cretaceous taxa Elsornis and Halimornis, and Eoenantiornis 685 from the Jehol. Currently, it would be impossible to provide unambiguous support for 686 Halimornis or Enantiophoenix as avisaurids given that these taxa do not preserve elements 687 critically necessary to assign specimens to this clade (namely the tarsometatarsus, which is only 688 partially preserved in Enantiophoenix and absent in Halimornis). The geographic distribution of 689 taxa closely related to the Avisauridae (spanning nearly every continent yielding enantiornithines) provides no clues as to the origin of this clade. Other purportedly 'avisaurid-

691 like' taxa are resolved further down the tree: Concornis is resolved with other Early Cretaceous 692 enantiornithines, potentially closely related to Cathayornis from the Jehol and the sympatric 693 Eoalulavis; a Bauxitornis + Gobipteryx clade forms the outgroup to the Concornis clade, 694 ambiguously supported by two synapomorphies $(249: 1 ; 240: 1)$, neither of which is preserved in 695 either taxon. Although Mystiornis is resolved as an enantiornithine, this unusual specimen 696 requires further research to better understand the apparently bizarre pattern of fusion and its true 697 phylogenetic affinity. 
699

700

701

702

703

704

705

706

707

708

709

710

711

712

713

714

715

716

717

718

719

720

721

722

723

724

725

726

727

728

729

Revised Systematic Paleontology

GETTYIA GEN. NOV.

Etymology: Named in honor of Mike Getty, a great friend, technician, and field

paleontologist, who is dearly missed.

Diagnosis: As for the type and only known species, given below.

GETTYIA GLORIAE (Varricchio \& Chiappe 1995) new comb.

Holotype: MOR 553E/6.19.91.64, a three-dimensional tarsometatarsus missing part of metatarsal IV.

Type horizon and locality: Upper Cretaceous (Campanian) Two Medicine Formation, MOR locality TM-068, Glacier County, Montana, USA.

Diagnosis: small avisaurid enantiornithine with the following unique combination of features: dorsal surface of the tarsometatarsus strongly inclined; attachment for the $m$. tibialis cranialis located beyond the midpoint of the tarsometatarsus; and distal vascular foramen completely closed by metatarsal IV.

\section{Avisaurid diversity}

For taxonomic purposes, comparison between avisaurids is limited to the tarsometatarsus (Fig. 15; Table 2); this element in UCMP139500 is very similar to Avisaurus archibaldi and Gettyia gloriae (formerly A. gloriae), but differs in several features which justify the erection of a new taxon, Mirarce eatoni (gen. et sp. nov). Even within the tarsometatarsus alone, the Avisauridae display considerable variation that includes differences both obvious (e.g., position of the tubercle for the $m$. tibialis cranialis, proximal foramen between metatarsals III and IV) and subtle (e.g., shapes of the metatarsal trochlea). The tarsometatarsus of UCMP139500 is intermediate in size between that of Avisaurus archibaldi and Gettyia gloriae. The metatarsals of A. archibaldi are fused along the proximal fifth of their lengths; in the smaller Gettyia metatarsals III and IV are also distally fused indicating that differences in body size between avisaurids species cannot be explained by ontogeny. UCMP 139500 does not demonstrate such 
730 extensive fusion of the metatarsals, and is instead characterized by fusion limited to the proximal

731 end of the element as in Soroavisaurus, Initiornis, and Early Cretaceous enantiornithines

732 (O’Connor 2009). Because the distal tarsals are fused to the metatarsals in UCMP 139500, body

733 size is not expected to change substantially - this individual clearly does not represent a juvenile.

734 In Early Cretaceous enantiornithines, the proximal tarsals appear to only fuse when the bird

735 reaches skeletal maturity after several years of growth (Hu and O'Connor 2017). However,

736 increased fusion between the metatarsals and slight increase in size during later ontogeny are

737 both possible.

738 The proximal articular surface of the tarsometatarsus is similar in Mirarce and Avisaurus,

739 which differ from the much smaller Gettyia, thus supporting our reassignment of this species to a

740 new genus. In proximal view the articular surface in UCMP139500 and Avisaurus archibaldi are

741 "bean-shaped" with slight concavities on the midline of the dorsal and plantar margins. A slight

742 concavity is present on the plantar margin in Gettyia and Soroavisaurus but the dorsal margin is

743 convex throughout. In Mirarce and Avisaurus the medial and lateral margins of the proximal

744 articular surface are weakly tapered medially and laterally respectively (defining a blunt $80-90^{\circ}$

745 angle), whereas in Gettyia the medial and lateral margins are rounded.

746 The tubercle for the attachment of the $m$. tibialis cranialis is enlarged in all avisaurids but

747 its position on metatarsal II relative to the proximal end varies among taxa. It is located at the

748 midpoint in Mirarce, but more proximally located in Avisaurus and Soroavisaurus and more

749 distally located in Gettyia. Given that small differences in the position of this muscle attachment

750 can have great effect on the moment arm generated by this muscle (O'Connor, Averianov et al.

751 2014), differences in the position of this tubercle suggest that pedal function in the Avisauridae

752 was quite varied, possibly reflecting ecological diversity (Zeffer and Norberg 2003).

753 In Mirarce, a very narrow fenestration is present between metatarsals III and IV,

754 although we consider this to be a diagenetic artifact and suggest the metatarsals instead would

755 have articulated tightly along their entire lengths in vivo. Regardless, this is distinct from the

756 fenestrated condition of Soroavisaurus australis caused by lateral curvature of metatarsal IV.

757 This feature, also present in Intiornis, is resolved as a synapomorphy of South American

758 avisaurids. The medial edge of metatarsal II in Mirarce is straight, whereas in Avisaurus there is

759 a curved expansion at its midpoint (the result of a hypertrophied ligamental fossa). This fossa is 
760 flatter in Mirarce. The plantar surface of metatarsal II is flat in Gettyia whereas a medial plantar

761 crest is present in Avisaurus and Soroavisaurus; the crest is only weakly developed in Mirarce.

762 The metatarsal II trochlea is distinctly expanded in Avisaurus and Soroavisaurus such

763 that the medial condyle is medially splayed. In Gettyia the trochlea has a more normal

764 appearance with a flat dorsal margin and subequal condyles. In Mirarce, this condition is

765 intermediate; although the condyles are asymmetrical, it is not developed to the extent in

766 Avisaurus and the trochlea maintains a relatively normal appearance in distal view. A metatarsal

767 II trochlea that is wider than that of metatarsal III is resolved as a synapomorphy of the polytomy

768 that includes Mystiornis and the Avisauridae. The medial condyle of the metatarsal III trochlea is

769 modified in all avisaurids although there is some variation. The intercondylar groove is poorly

770 developed on the dorsal surface of Avisaurus but well-developed and continuous with a small

771 dorsal trochlear depression in Gettyia and Mirarce. In Avisaurus archibaldi the medial condyle

772 projects farther distally and plantarly than the lateral condyle, whereas in Gettyia and Mirarce

773 the two condyles are equal in distal extent and the plantar projection of the medial condyle is less

774 extreme. The avisaurid metatarsal IV trochlea is described as crescent shaped in distal view -

775 this is most apparent in Avisaurus. This morphology is weaker in Mirarce and Gettyia, where the

776 condyle is less mediolaterally compressed. A medially excavated metatarsal IV trochlea is

777 resolved as a synapomorphy of North American avisaurids. In Avisaurus the trochlea is

778 proportionately wider and the distal margin is angled medioproximally - laterodistally, whereas

779 in Mirarce, Gettyia, and Soroavisaurus the distal margin of metatarsal IV trochlea is rounded in

780 dorsal view. In dorsal view this trochlea is expanded medially to contact metatarsal III and

781 distally enclose a vascular foramen in Avisaurus, Gettyia, and Soroavisaurus, a structure that is

782 lacking in Mirarce. In Mirarce the proximomedial margin of the metatarsal IV trochlea bears

783 only a very small, medially directed tubercle in place of the large flange observed in Avisaurus,

784 Gettyia, and Soroavisaurus. These differences strongly support our referral of Gettyia to a new

785 genus, also reinforced through cladistic analysis.

$786 \quad$ Evolutionary Trends

787 The Enantiornithes have a long evolutionary history, first appearing in the $131 \mathrm{Ma}$

788 Huajiying Formation in China and surviving up to the K-Pg boundary, documented in the end

789 Maastrichtian Hell Creek Formation. Attempts to understand evolutionary trajectories during the

79065 million year (plus) of history of this clade have been obfuscated by the poor resolution of the 
791 Late Cretaceous fossil record. Despite the paucity of Late Cretaceous specimens, several trends

792 have been suggested: a general increase in range of body sizes, particularly at the upper limit; a

793 greater deree of fusion of compound elements, and the appearance of advanced flight-related

794 features evolved in parallel to the neornithine lineage (e.g., manual reduction, loss of teeth,

795 increase in size of sternal keel)(Chiappe and Walker 2002, O’Connor 2009). As one of the most

796 complete known Late Cretaceous enantiornithines, Mirarce contributes data that significantly

797 expands our understanding of evolutionary trajectories in the Enantiornithes. Mirarce is much

798 larger than any Early Cretaceous enantiornithine (close to turkey-sized), in keeping with

799 observations that some Late Cretaceous taxa achieved much larger body size.

800 Fusion is absent in the distal metatarsals as in other enantiornithines. This absence of

801 fusion may be related to the protracted skeletal development observed in enantiornithines

802 (Chinsamy, Chiappe et al. 1995). The well-fused proximal carpometacarpus and tarsometatarsus,

803 distal tibiotarsus and fused pelvic girdle observed in Mirarce are also found in some Early

804 Cretaceous specimens (e.g. Qiliania, Concornis), thus no strong trend towards increased fusion

805 during enantiornithine evolution is observed. For example, the distal carpometacarpus remains

806 unfused in Late Cretaceous taxa (Elsornis, Neuquenornis, and Enantiornis) and complete fusion

807 of the tarsometatarsus is not observed in any taxon, despite the fact this element is fully fused

808 even in the earliest Cretaceous ornithuromorphs (Wang, Zheng et al. 2015b). This cannot be

809 considered a product of preservation or sampling because ornithuromorphs are known from far

810 fewer specimens. Only the skull displays new instances of fusion, with the premaxillae and

811 dentaries rostrally fused in all Late Cretaceous specimens. Although rare, fusion of the

812 premaxillae is present in some Early Cretaceous enantiornithines, but no Early Cretaceous

813 specimen has an extensive mandibular symphysis like that observed in Gobipteryx and

814 neornithines. Overall, however, degree fusion of compound bones remains similar across the

815 clade Enantiornithes regardless of geological age.

816 Although incomplete, the preserved sternal fragment of Mirarce indicates the presence of

817 a well-developed ventral keel. This preserved morphology is very similar to that observed in

818 Neuquenornis. In contrast, Elsornis reveals a condition similar to that of Early Cretaceous

819 enantiornithines with a poorly developed, cranially forked carina (Chiappe, Suzuki, et al., 2007).

820 With the exception of the ratites, all living birds possess a large ventral keel. The poorly

821 developed keel in Elsornis may similarly be related to inferences that this taxon was flightless, or 
822 suggests this taxon falls outside the lineage in which an unforked, rostrally extending keel

823 evolved in the Enantiornithes (in parallel to the Ornithuromorpha). The former hypothesis is

824 supported by this phylogenetic analyses (Fig. 18), which places Elsornis in a clade of derived

825 taxa including the Avisauridae (O'Connor and Zhou 2013). The distribution of advanced sternal

826 morphologies among derived enantiornithines is unknown, currently recognized only within the

827 Avisauridae and may potentially represent a synapomorphy of this lineage. However, we

828 consider it likely that flight-related specializations like, such as a ventrally deep keel has, had a

829 broader distribution within the Enantiornithes and may have evolved multiple times.

830 Other derived features of the flight apparatus limited to the Avisauridae include a narrow

831 furcula (though also seen in Neuquenornis) and the presence of remige papillae, identified for the

832 first time in Mirarce. In modern birds, the function of these osteological structures is to provide a

833 reinforced attachment surface for the calami of the secondary remiges, and in doing so to transfer

834 aerodynamic forces from the feathers to the wing skeleton (Edington and Miller 1942,

835 Hieronymus 2015). Turner et al. (2007) report a statistically significant correlation between the

836 reduction or loss of flight capabilities and the reduction or absence of ulnar remiges in modern

837 birds, concluding that the prominence of this osteological characteristic is a good proxy for flight

838 capacity. We therefore conclude, based on the remarkable size and prominence of the remige

839 papillae observed in Mirarce (Fig. 9), that this taxon had advanced capacities for powered flight.

840 This further supports hypotheses that at least some lineages of enantiornithines convergently

841 achieved more advanced aerial capabilities by the Late Cretaceous. In contrast, the pygostyle

842 morphology of Mirarce exhibits the typical, proximally-forked and distally-constricted

843 morphology that characterizes nearly all enantiornithines including Halimornis and Parvavis,

844 indicating that this feature was static in all known lineages extending into the Late Cretaceous.

845 Notably, the pedal phalanges in Mirarce are not markedly elongate as in other

846 enantiornithines. However, compared to Cretaceous members of the crown-ward clade the pedal

847 unguals in Mirarce are strongly curved, a morphology also common in enantiornithines.

848 Differences in hindlimb function are suggested by the numerous scars and rugosities present on

849 the femur, hinting at very different musculature - and possibly also ecological habits - than in

850 Early Cretaceous enantiornithines.

851 Considering that the Cretaceous evolutionary history of the Enantiornithes is nearly as

852 long as that of Neornithes, there is surprisingly little observable morphological variation through 
853 time, though significantly, elements that show the greatest variation in Early Cretaceous avifauna

854 (such as the skull and sternum) are not well known in the Late Cretaceous enantiornithine fossil

855 record. The most extreme morphological diversity resides in the tarsometatarsi from the Lecho

856 Formation described by Chiappe (1993). These data do indeed suggest that Late Cretaceous

857 enantiornithines in this avifauna were ecologically diverse. Attempts to understand evolutionary

858 trends in Enantiornithes remain impeded by the limited Late Cretaceous fossil record, thus the

859 information preserved in the skeleton of Mirarce is all the more critical, paving the way for

860 future significant advances in this area.

861

862 Acknowledgements

863 We are grateful to David Strauss for photographs of the specimen, Gregory Arena for the

864 technical drawings of the specimen, Scott Hartman for the customized skeletal reconstruction,

865 Brian Engh for the living reconstruction artwork, and Steve Henriksen for facilitating the

866 commission of Brian's art. We also thank Peter Kloess for photographing ulnar quill knobs in the

867 UCMP comparative collection, Andrew McDonald for creative assistance with naming the new

868 taxon, Tom Stidham and Nikita Zelenkov for helpful discussions. Finally, we are grateful to

869 Nikita Zelenkov, Luis Chiappe, and one anonymous reviewer for their constructive criticism and

870 helpful comments during the formal review process.

871

872

873

874

875

876 
877

878

879

880

881

882

883

884

885

886

887

888

889

890

891

892

893

894

895

896

897

898

899

900

901

902

903

904

905

906

907

908

909

910

911

912

913

914

915

916

917

918

919

920

921

922

Works Cited

Baumel, J. J., A. S. King, J. E. Breazile, H. E. Evans, and J. C. Vanden Berge eds. 1993. Handbook of Avian Anatomy: Nomina Anatomica Avium, Second Edition, Vol. 23. Nuttall Ornithological Club, Cambridge.

Brett-Surman MK, and Paul GS. 1985. A new family of bird-like dinosaurs linking Laurasia and Gondwanaland. Journal of Vertebrate Paleontology 5:133-138.

Brodkorb P. 1976. Discovery of a Cretaceous bird, apparently ancestral to the orders Coraciiformes and Piciformes (Aves: Carinatae). Smithsonian Contributions to Paleobiology 27:67-73.

Buffetaut, E. 1998. First evidence of enantiornithine birds from the Upper Cretaceous of Europe: postcranial bones from Cruzy (Herault, southern France). Oryctos 1:131-136.

Buffetaut E. 2010. A basal bird from the Campanian (Late Cretaceous) of Dinosaur Provincial

Park (Alberta, Canada). Geological Magazine 147:469-472. 10.1017/S0016756810000129

Cau A, and Arduini P. 2008. Enantiophoenix electrophylagen. et sp. nov. (Aves, Enantiornithes)

from the Upper Cretaceous (Cenomanian) of Lebanon and its phylogenetic relationships. Atti

della Società Italiana di Scienze Naturali e del Museo Civico di Storia Naturale in Milano 149:293-324.

Chiappe LM. 1992. Enantiornithine (Aves) tarsometatarsi and the avian affinities of the Late Cretaceous Avisauridae. Journal of Vertebrate Paleontology 12:344-350.

Chiappe LM. 1993. Enantiornithine (Aves) tarsometatarsi from the Cretaceous Lecho Formation of northwestern Argentina. American Museum Novitates 3083:1-27.

Chiappe, L. M. 1996. Late Cretaceous birds of southern South America: anatomy and systematics of Enantiornithes and Patagopteryx deferrariisi. Münchner Geowissenschaften Abhandlungen 30:203-244.

Chiappe LM, and Calvo JO. 1994. Neuquenornis volans, a new Late Cretaceous bird (Enantiornithes, Avisauridae) from Patagonia, Argentina. Journal of Vertebrate Paleontology 14:230-246.

Chiappe LM, Lamb JP, and Ericson PGP. 2002. New enantiornithine bird from the marine Upper Cretaceous of Alabama. Journal of Vertebrate Paleontology 22:170-174. 10.1671/02724634(2002)022[0170:NEBFTM]2.0.CO;2

Chiappe LM, Suzuki S, Dyke GJ, Watabe M, Tsogtbaatar K, and Barsbold R. 2007. A new enantiornithine bird from the Late Cretaceous of the Gobi Desert. Journal of Systematic Palaeontology 5:193-208. 10.1017/S1477201906001969

Chiappe LM, and Walker CA. 2002. Skeletal morphology and systematics of the Cretaceous Euenantiornithes (Ornithothoraces: Enantiornithes). In: Chiappe LM, and Witmer LM, eds. Mesozoic Birds: Above the Heads of Dinosaurs. Berkeley: University of California Press, 240267.

Chiappe LM, and Witmer LM. 2002. Mesozoic Birds: Above the Heads of Dinosaurs. California: University of California Press.

Chinsamy A, Chiappe LM, and Dodson P. 1995. Mesozoic avian bone microstructure: Physiological implications. Paleobiology 21:561-574.

Dyke GJ, and Ösi A. 2010. A review of Late Cretaceous fossil birds from Hungary. Geological Journal 45(4): 434-444.

Edington GH, and Miller AE. 1942. XII.-The Avian Ulna: Its Quill-Knobs. Proceedings of the Royal Society of Edinburgh, Section B: Biological Sciences 61:138-148. 
923 Elzanowski A. 1976. Results of the Polish Mongolian paleontological expeditions, Part 5:

924 preliminary note on the palaeognathous bird from the Upper Cretaceous of Mongolia.

925 Palaeontologia Polonica 30:103-109.

926 Elzanowski, A. 1981. Embryonic bird skeletons from the Late Cretaceous of Mongolia.

927 Palaeontologica Polonica 42:147-179.

928 Farke AA, and Patel PP. 2012. An enantiornithine bird from the Campanian Kaiparowits

929 Formation of Utah, USE. Cretaceous Research:1-4.

930 Field, D. J., M. Hanson, D. A. Burnham, L. E. Wilson, K. Super, D. Ehret, J. A. Ebersole, and

931 B.-A. Bhullar. 2018. Complete Ichthyornis skull illuminates mosaic assembly of the avian head.

932 Nature 557:96.

933 Goloboff P, Farris J, and Nixon KC. 2008a. TNT, a free program for phylogenetic analysis.

934 Cladistics 24:774-786.

935 Goloboff, P. A., J. M. Carpenter, J. S. Arias, and D. R. M. Esquivel. 2008b. Weighting against

936 homoplasy improves phylogenetic analysis of morphological data sets. Cladistics 24:1-16.

937 Hieronymus TL. 2015. Qualitative skeletal correlates of wing shape in extant birds (Aves:

938 Neoaves). BMC Evolutionary Biology 15:30.

$939 \mathrm{Hu} \mathrm{H}$, and O'Connor JK. 2017. First species of Enantiornithes from Sihedang elucidates skeletal

940 development in Early Cretaceous enantiornithines. Journal of Systematic Palaeontology 15:909-

941926.

942 Hu, H., Z.-H. Zhou, and J. K. O'Connor. 2014. A subadult specimen of Pengornis and character

943 evolution in Enantiornithes. Vertebrata Palasiatica 52:77-97.

944 Hutchison JH. 1993. Avisaurus: a "dinosaur" grows wings. Journal of Vertebrate Paleontology

945 13:43.

946 Ji S, Atterholt J, O'Connor JK, Lamanna MC, Harris JD, Li D, You H, and Dodson P. 2011. A

947 new, three-dimensionally preserved enantiornithine bird (Aves: Ornithothoraces) from Gansu

948 Province, north-western China. Zoological Journal of the Linnean Society 162:201-219.

949 10.1111/j.1096-3642.2010.00671.x

950 Jiang B, Zhao T, Regnault S, Edwards NP, Kohn SC, Li Z, Wogelius RA, Benton MJ, and

951 Hutchinson JR. 2017. Cellular preservation of musculoskeletal specializations in the Cretaceous

952 bird Confuciusornis. Nature Communications 8:14779.

953 Kurochkin EN. 1999. A new large enantiornithid from the upper cretaceous of Mongolia. Trudy

954 Zoologicheskogo Instituta 277:130-141.

955 Kurochkin EN, Zelenkov NV, Averianov AO, and Leshchinskiy SV. 2011. A new taxon of birds

956 (Aves) from the Early Cretaceous of Western Siberia, Russia. Journal of Systematic

957 Palaeontology 9:109-117. 10.1080/14772019.2010.522202

958 Kurochkin EN, Chatterjee S, Mikhailov KE. 2013. An embryonic enantiornithine bird and

959 associated eggs from the Cretaceous of Mongolia. Paleontological Journal 47(11):1252-69.

960 Linnaeus C. 1758. Systema naturae per regna tria naturae, secundum classes, ordines, genera,

961 species, cum characteribus, differentiis, synonymis, locis. Stockholm: Laurentii Salvii.

962 Livezey BC, and Zusi RL. 2007. Higher-order phylogeny of modern birds (Theropoda, Aves :

963 Neornithes) based on comparative anatomy. II. Analysis and discussion. Zoological Journal of

964 the Linean Society 149:1-95.

965 Longrich NR, Tokaryk T, and Field DJ. 2011. Mass extinction of birds at the Cretaceous-

966 Paleogene (K-Pg) boundary. Proceedings of the National Academy of Sciences 108:15253-

967 15257. 10.1073/pnas.1110395108 
968 Mosto MC, Carril J, and Picasso MBJ. 2013. The hindlimb myology of Milvago chimango

969 (Polyborinae, Falconidae). Journal of Morphology 274:1191-1201. 10.1002/jmor.20172

970 Norell M, Makovicky PJ, and Project M-AMP. 1999. Important features of the dromaeosaurid

971 skeleton. 2, Information from newly collected specimens of Velociraptor mongoliensis.

972 American Museum Novitates; no. 3282.

973 Novas FE, Agnolín FL, and Scanferla CA. 2010. New enantiornithine bird (Aves,

974 Ornithothoraces) from the Late Cretaceous of NW Argentina. Comptes rendus - Palevol 9:499-

975 503. 10.1016/j.crpv.2010.09.005

976 O'Connor, J. K. 2009. A systematic review of Enantiornithes (Aves: Ornithothoraces): In

977 Geological Sciences, Vol. Ph.D., pp. 600. University of Southern California, Los Angeles.

978 O'Connor, J. 2012. A revised look at Liaoningornis longidigitrus (Aves). Vertebrata Palasiatica

979 5:25-37.

980 O'Connor JK, Averianov AO, and Zelenkov NV. 2014. A confuciusornithiform (Aves,

981 Pygostylia)-like tarsometatarsus from the Early Cretaceous of Siberia and a discussion of the

982 evolution of avian hind limb musculature. Journal of Vertebrate Paleontology 34:647-656.

983 O'Connor JK, Chiappe LM, and Bell A. 2011. Pre-modern birds: Avian divergences in the

984 Mesozoic. In: Dyke G, and Kaiser G, eds. Living Dinosaurs: The Evolutionary History of

985 Modern Birds: John Wiley \& Sons, Ltd., 39-114.

986 O'Connor JK, Wang X, Chiappe LM, Gao C, Meng Q, Cheng X, and Liu J. 2009. Phylogenetic

987 support for a specialized clade of Cretaceous enantiornithine birds with information from a new

988 species. Journal of Vertebrate Paleontology 29:188-204.

989 O'Connor JK, and Zhou Z. 2013. A redescription of Chaoyangia beishanensis(Aves) and a

990 comprehensive phylogeny of Mesozoic birds. Journal of Systematic Palaeontology 11:889-906.

991 O'Connor PM, and Forster CA. 2010. A Late Cretaceous (Maastrichtian) avifauna from the

992 Maevarano Formation, Madagascar. Journal of Vertebrate Paleontology 30:1178-1201.

$993 \quad 10.1080 / 02724634.2010 .483544$

994 Ortega F, Escaso F, and Sanz JL. 2010. A bizarre, humped Carcharodontosauria (Theropoda)

995 from the Lower Cretaceous of Spain. Nature 467:203.

996 Ösi A. 2008. Enantiornithine bird remains from the Late Cretaceous of Hungary. Oryctos 7:55-

99760.

998 Panteleev, A. (2018). Morphology of the Coracoid of Late Cretaceous Enantiornithines (Aves:

999 Enantiornithes) from Dzharakuduk (Uzbekistan). Paleontological Journal 52(2): 201-207.

1000 Roberts EM, Deino AD, and Chan MA. 2005. 40Ar/39Ar age of the Kaiparowits Formation,

1001 southern Utah, and correlation of coeval strata and faunas along the margin of the Western

1002 Interior Basin. Cretaceous Research 26.

1003 Sanz JL, Buscalioni AD. 1992. A new bird from the Early Cretaceous of Las Hoyas, Spain, and

1004 the early radiation of birds. Palaeontology 35(4):829-45.

1005 Sanz J, Chiappe LM, and Buscalioni AD. 1995. The osteology of Concornis lacustris(Aves:

1006 Enantiornithes) from the Lower Cretaceous of Spain and a reexamination of its phylogenetic

1007 relationships. American Museum Novitates 3133:1-23.

1008 Sereno PC, and Chenggang R. 1992. Early evolution of avian flight and perching: new evidence

1009 from the Lower Cretaceous of China. Science 255:845-848.

1010 Steadman, D. W. 1983. Commentary; pp. 338-344 in A. H. Brush, and G. A. Clark, Jr. (eds.),

1011 Perspectives in Ornithology: Essays presented for the Centennial of the American Ornithological

1012 Union. Cambridge University Press, Cambridge. 
1013 Turner AH, Makovicky PJ, and Norell MA. 2007. Feather quill knobs in the dinosaur

1014 Velociraptor. Science 317:1721-1721.

1015 Tykoski RS, and Fiorillo AR. 2010. An enantiornithine bird from the lower middle Cenomanian

1016 of Texas. Journal of Vertebrate Paleontology 30:288-292. 10.1080/02724630903416068

1017 Varricchio DJ, and Chiappe LM. 1995. A new enantiornithine bird from the Upper Cretaceous

1018 Two Medicine Formation of Montana. Journal of Vertebrate Paleontology 15:201-204.

1019 Venden Berge JC, and Zweers GA. 1993. Myologia. In: Baumel J, King A, Breazile J, Evans H, 1020 and Vanden Berge J, eds. Handbook of avian anatomy: Nomina Anatomica Avium, Publication

1021 No 23. Cambridge, Massachusetts, USA: Publications of the Nuttal Ornithological Club, 189-

1022247.

1023 Walker CA. 1981. New subclass of birds from the Cretaceous of South America. Nature 292:51-

102453.

1025 Walker CA, Buffetaut E, and Dyke GJ. 2007. Large euenantiornithine birds from the Cretaceous

1026 of southern France, North America and Argentina. Geological Magazine 144:977-986.

1027 10.1017/S0016756807003871

1028 Walker CA, and Dyke GJ. 2009. Euenantiornithine birds from the Late Cretaceous of El Brete

1029 (Argentina). Irish Journal of Earth Sciences 27:15-62.

1030 Wang M, Zhou Z, and Xu G. 2014. The first enantiornithine bird from the Upper Cretaceous of

1031 China. Journal of Vertebrate Paleontology 34:135-145.

1032 Wang, M., J. K. O'Connor, N. Z. Zelenkov, and Z.-H. Zhou. 2014. A new diverse enantiornithine

1033 family (Bohaiornithidae fam. nov.) from the Lower Cretaceous of China with information from

1034 two new species. Vertebrata Palasiatica 52:31-76.

1035 Wang, M., D.-Q. Li, J. K. O'Connor, Z.-H. Zhou, and H.-L. You. 2015a. Second species of

1036 enantiornithine bird from the Lower Cretaceous Changma Basin, northwestern China with

1037 implications for the taxonomic diversity of the Changma avifauna. Cretaceous Research 55:56-

103865.

1039 Wang, M., X.-T. Zheng, J. K. O'Connor, G. T. Lloyd, X.-L. Wang, Y. Wang, X.-M. Zhang, and

1040 Z.-H. Zhou. 2015b. The oldest record of Ornithuromorpha reveals heterogeneous rates of

1041 morphological evolution among Early Cretaceous birds. Nature Communications 6:6987.

1042 Wang M, O'Connor JK, Pan Y, Zhou Z. 2017. A bizarre Early Cretaceous enantiornithine bird

1043 with unique crural feathers and an ornithuromorph plough-shaped pygostyle. Nature

1044 communications 8:14141.

$1045 \mathrm{Xu}$, X. 2018. Mosaic evolution in birds: Brain vs. feeding apparatus. Science Bulletin.

1046 Zeffer, A., and U. M. L. Norberg. 2003. Leg morphology and locomotion in birds: requirements

1047 for force and speed during ankle flexion. Journal of Experimental Biology 206:1085-1097.

1048 Zhou Z, and Zhang F. 2007. Mesozoic birds of China - a synoptic review. Frontiers of Biology

1049 in China 2:1-14.

1050 Zhou Z-H, Zhang F-C, and Li Z-H. 2009. A new basal ornithurine bird (Jianchangornis

1051 microdonta gen. et sp. nov.) from the Lower Cretaceous of China. Vertebrata PalAsiatica 4:299-

1052310.

1053 


\section{Table $\mathbf{1}$ (on next page)}

Measurements of skeletal elements of Mirarce eatoni.

"Length" refers to proximodistal/craniocaudal length; "width" refers to the width of the midshaft/midpoint of the element unless otherwise specified. All measurements are given in units of $\mathrm{mm}$. 
1

\begin{tabular}{|l|c|}
\hline Measurement & $\begin{array}{c}\text { Mirarce } \\
\text { eatoni }\end{array}$ \\
\hline Axis, length & 18.1 \\
\hline Pygostyle, length & 37.9 \\
\hline $\begin{array}{l}\text { Coracoid, width } \\
\text { of sternal end }\end{array}$ & 27.0 \\
\hline Furcula, length & $\sim 65.9$ \\
\hline $\begin{array}{l}\text { Furcula, width of } \\
\text { omal tip (avrg.) }\end{array}$ & 7.7 \\
\hline $\begin{array}{l}\text { Furcula, width of } \\
\text { hypocleidium }\end{array}$ & 2.5 \\
\hline Scapula, length & $>63.2$ \\
\hline Scapula, width & 8.3 \\
\hline Humerus, length & 95.9 \\
\hline Humerus, width & 11.6 \\
\hline Ulna, width & $\sim 10.7$ \\
\hline Femur, length & 89.0 \\
\hline Femur, width & 8.4 \\
\hline $\begin{array}{l}\text { Tarsometatarsus, } \\
\text { length }\end{array}$ & 48.1 \\
\hline $\begin{array}{l}\text { Tarsometatarsus, } \\
\text { width }\end{array}$ & 10.9 \\
\hline
\end{tabular}

2

3

4 


\section{Table 2 (on next page)}

Comparative measurements of North American avisaurid tarsometatarsi (modified fromVaricchio \& Chiappe, 1995).

Measurements given in units of $\mathrm{mm}$. 
1

\begin{tabular}{|l|c|c|c|}
\hline \multicolumn{1}{|c|}{ Measurement } & $\begin{array}{c}\text { Mirarce eatoni } \\
\text { (UCMP 139500) }\end{array}$ & $\begin{array}{c}\text { Avisaurus } \\
\text { archibaldi } \\
\text { (UCMP 117600) }\end{array}$ & $\begin{array}{c}\text { Gettyia gloriae } \\
\text { (MOR 553E/6.19.91.64) }\end{array}$ \\
\hline Length, MTII & 44.1 & 68.7 & 28.4 \\
\hline Length, MTIII & 48.2 & 73.9 & 30.9 \\
\hline Length, MTIV & 45.9 & 67.8 & 28.5 \\
\hline $\begin{array}{l}\text { Width of proximal } \\
\text { end }\end{array}$ & 14.5 & 20.9 & 9.1 \\
\hline Width, midshaft & 10.9 & 16.6 & $\sim 6.4$ \\
\hline Width of distal end & 17.3 & 24.3 & 4.8 \\
\hline $\begin{array}{l}\text { Width of trochlea, } \\
\text { MTII }\end{array}$ & 7.1 & 9.9 & 4.0 \\
\hline $\begin{array}{l}\text { Width of trochlea, } \\
\text { MTIII }\end{array}$ & 6.3 & 8.4 & $\sim 2.5$ \\
\hline $\begin{array}{l}\text { Width of trochlea, } \\
\text { MTIV }\end{array}$ & 3.1 & 6.9 & 2.9 \\
\hline $\begin{array}{l}\text { Depth of trochlea, } \\
\text { MTII }\end{array}$ & 4.6 & 7.2 & 3.9 \\
\hline $\begin{array}{l}\text { Depth of trochlea, } \\
\text { MTIII }\end{array}$ & 5.8 & 9.9 & 4.3 \\
\hline $\begin{array}{l}\text { Depth of trochlea, } \\
\text { MTIV }\end{array}$ & 5.2 & 8.9 & 2.9 \\
\hline
\end{tabular}

2

3 
Figure 1

Map of the enantiornithine fossil record in North America.

Empty black circle - individual incomplete element. Filled black circle - individual complete element. Filled red circle - associated fragments and elements ( $<10 \%$ of skeleton preserved). Yellow star - associated fragments and elements (>10\% of skeleton preserved).

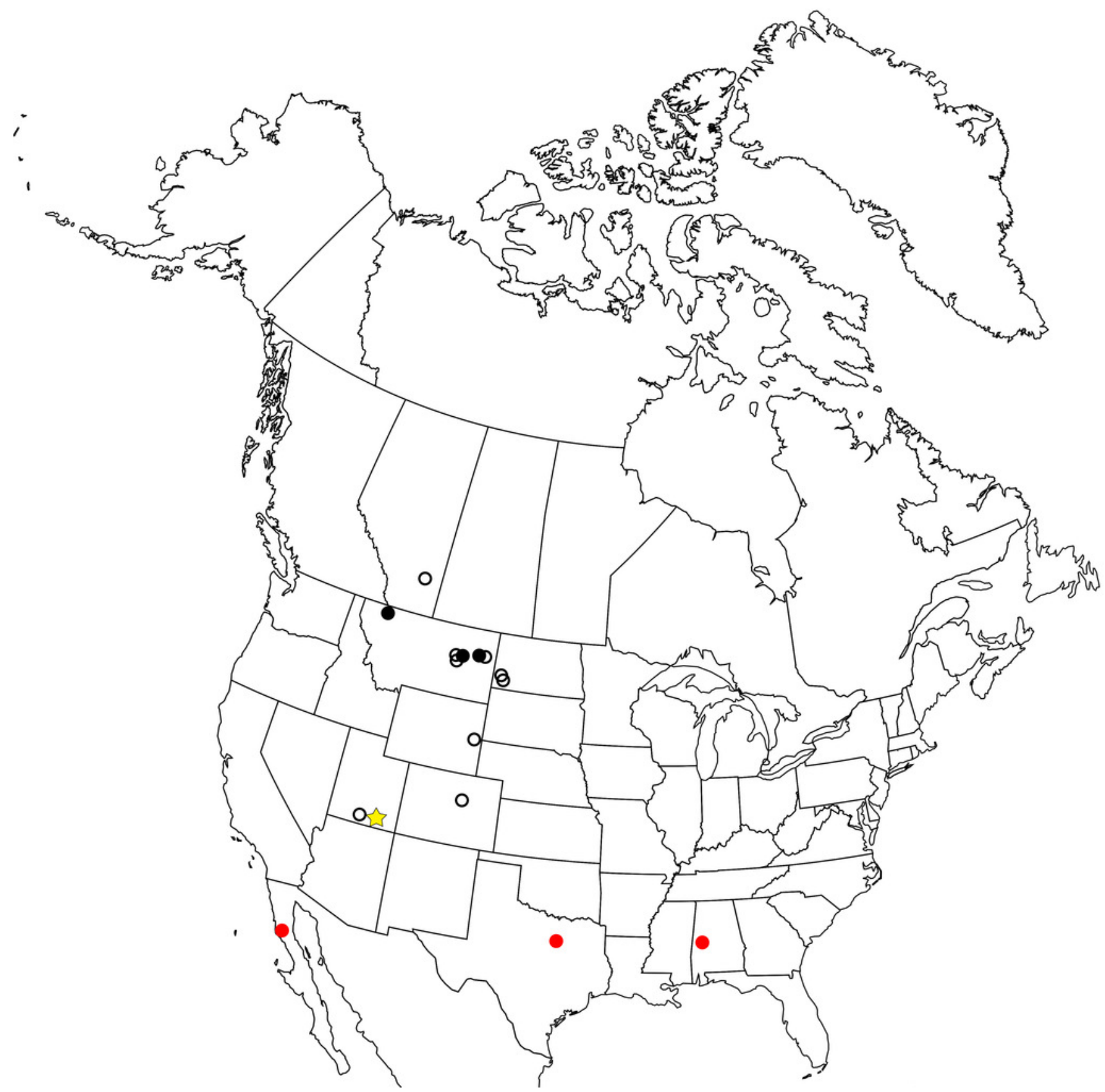




\section{Figure 2}

A sampling of the best-preserved cervical and thoracic vertebrae, including the axis.

(A) Axis in lateral view. (B) Axis in dorsal view. (C) Axis in caudal view. (D) Third cervical vertebra in lateral view. (E) Third cervical vertebra in ventral view. (F) Posterior cervical vertebra in lateral view. (G) Posterior cervical vertebra in ventral view. (H) Thoracic vertebra in lateral view. (I) Thoracic vertebra in ventral view. (J) Thoracic vertebra in anterior view. Abbreviations: ds, dens; ep, epipophysis; Ig, lateral groove; Ir, lateral ridge; pap, parapophysis; prz, prezygopophysis; poz, postzygopophysis; posterior shelf, ps; sp, spinous process; vp, ventral process. Scale bar equals $1 \mathrm{~cm}$. Photos: David Strauss.

*Note: Auto Gamma Correction was used for the image. This only affects the reviewing manuscript. See original source image if needed for review. 


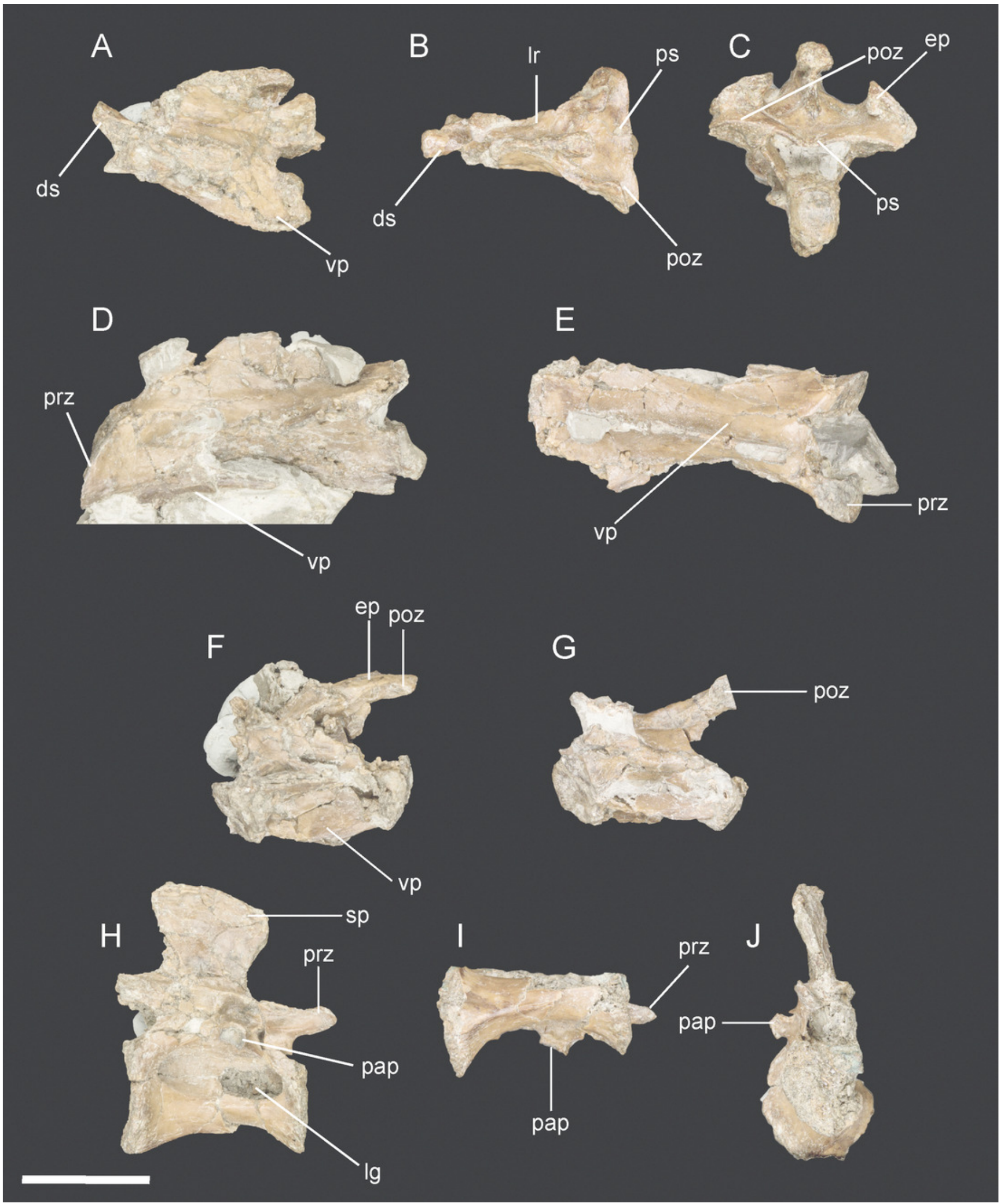




\section{Figure 3}

Pygostyle.

(A) Dorsal view. (B) Ventral view. (C) Left lateral view. (D) Right lateral view. (E) Cranial view. Abbreviations: df, dorsal fork; dlp, dorsolateral processes; mf, median furrow; vlp, ventrolateral processes. Scale bar equals $1 \mathrm{~cm}$. Photos: David Strauss. Illustrations: Gregory C. Arena. 

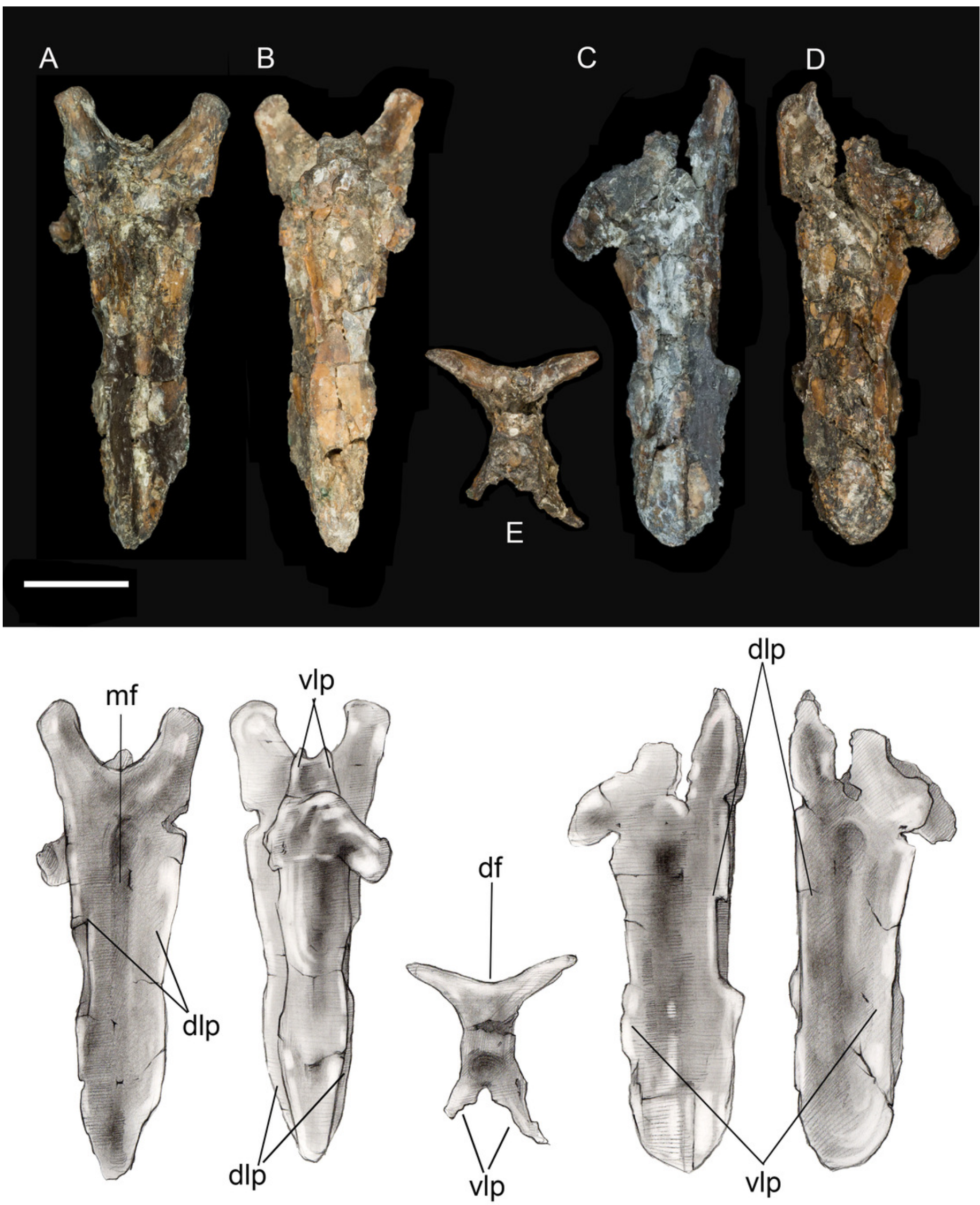


\section{Figure 4}

Furcula.

(A) Dorsal view. (B) Ventral view. Abbreviations: dg, dorsal groove; hyk, hypocleidial keel; imr, intermuscular ridge. Scale bar equals $1 \mathrm{~cm}$. Photos: David Strauss. Illustrations: Gregory C. Arena. 

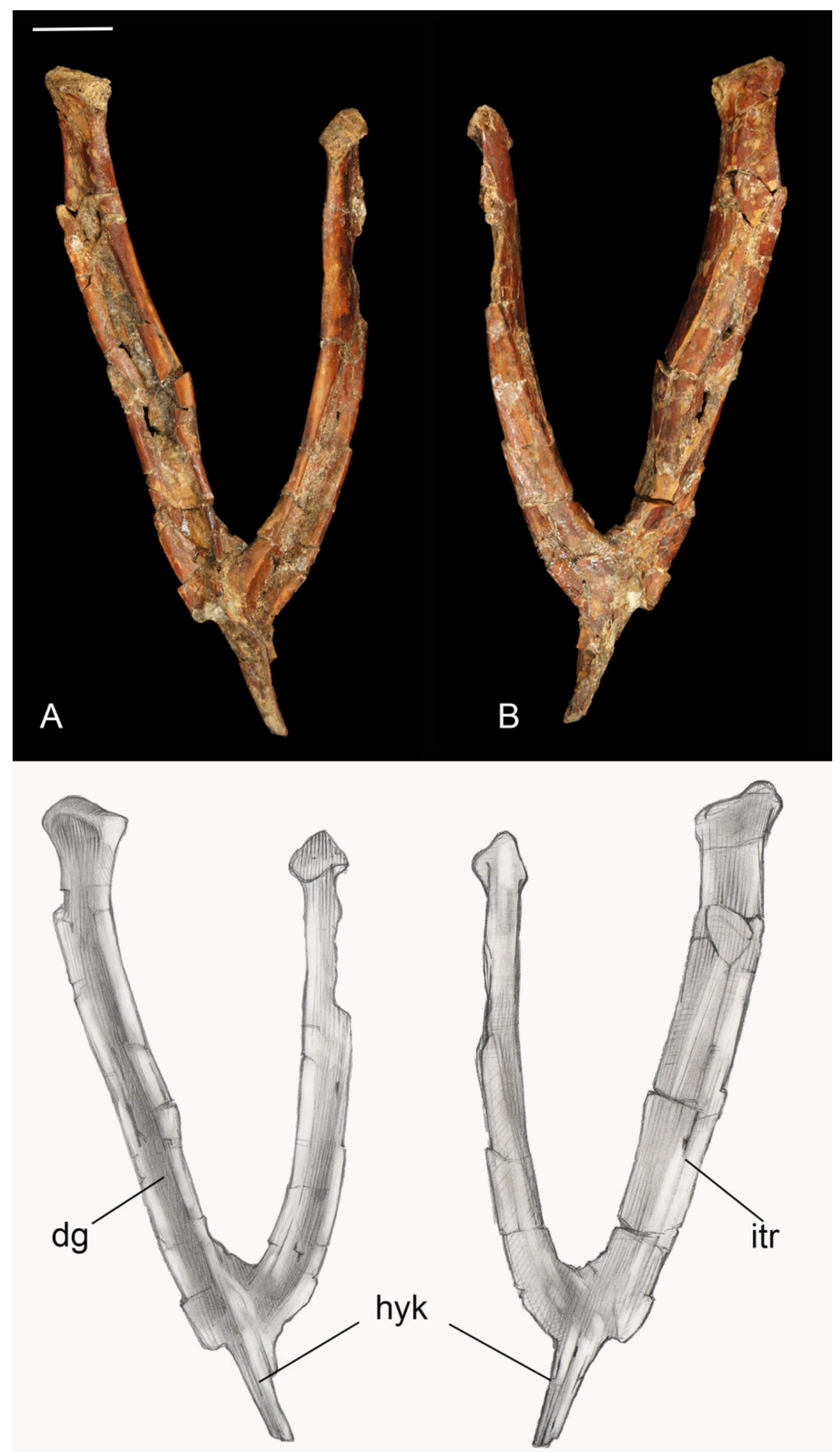

PeerJ reviewing PDF | (2018:02:25191:2:0:NEW 21 Sep 2018) 


\section{Figure 5}

Xiphoid process of sternum.

(A) Ventral view. (B) Left lateral view. (C) Ventral view. (D) Right lateral view. Abbreviations:

tk, terminal knob; vk, ventral keel. Scale bar equals $1 \mathrm{~cm}$. Photos: David Strauss. Illustrations:

Gregory C. Arena. 

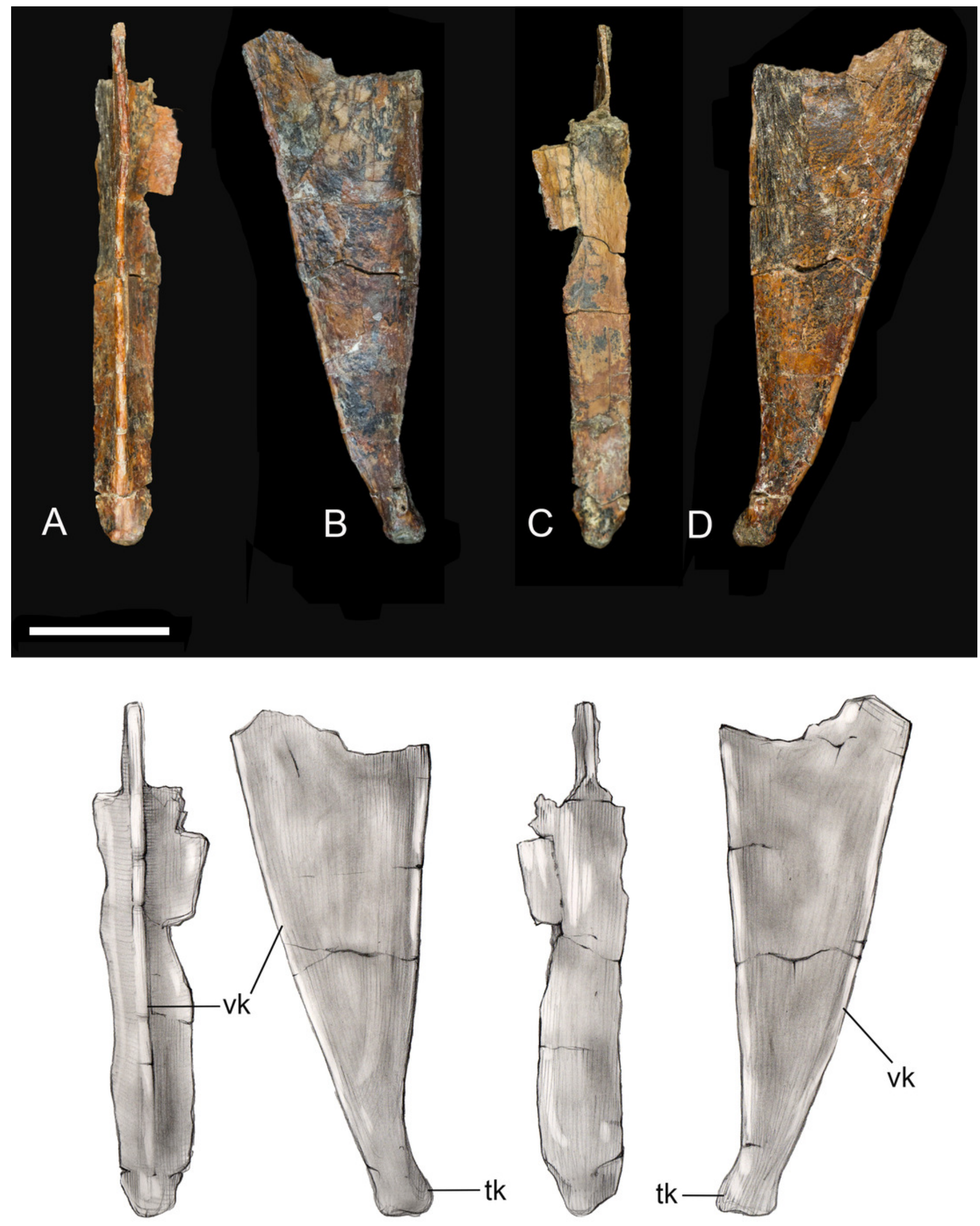


\section{Figure 6}

Left scapula.

(A) Medial view. (B) Lateral view. Abbreviations: $\mathrm{mf}$, medial fossa. Scale bar equals $1 \mathrm{~cm}$.

Photos: David Strauss. Illustrations: Gregory C. Arena. 

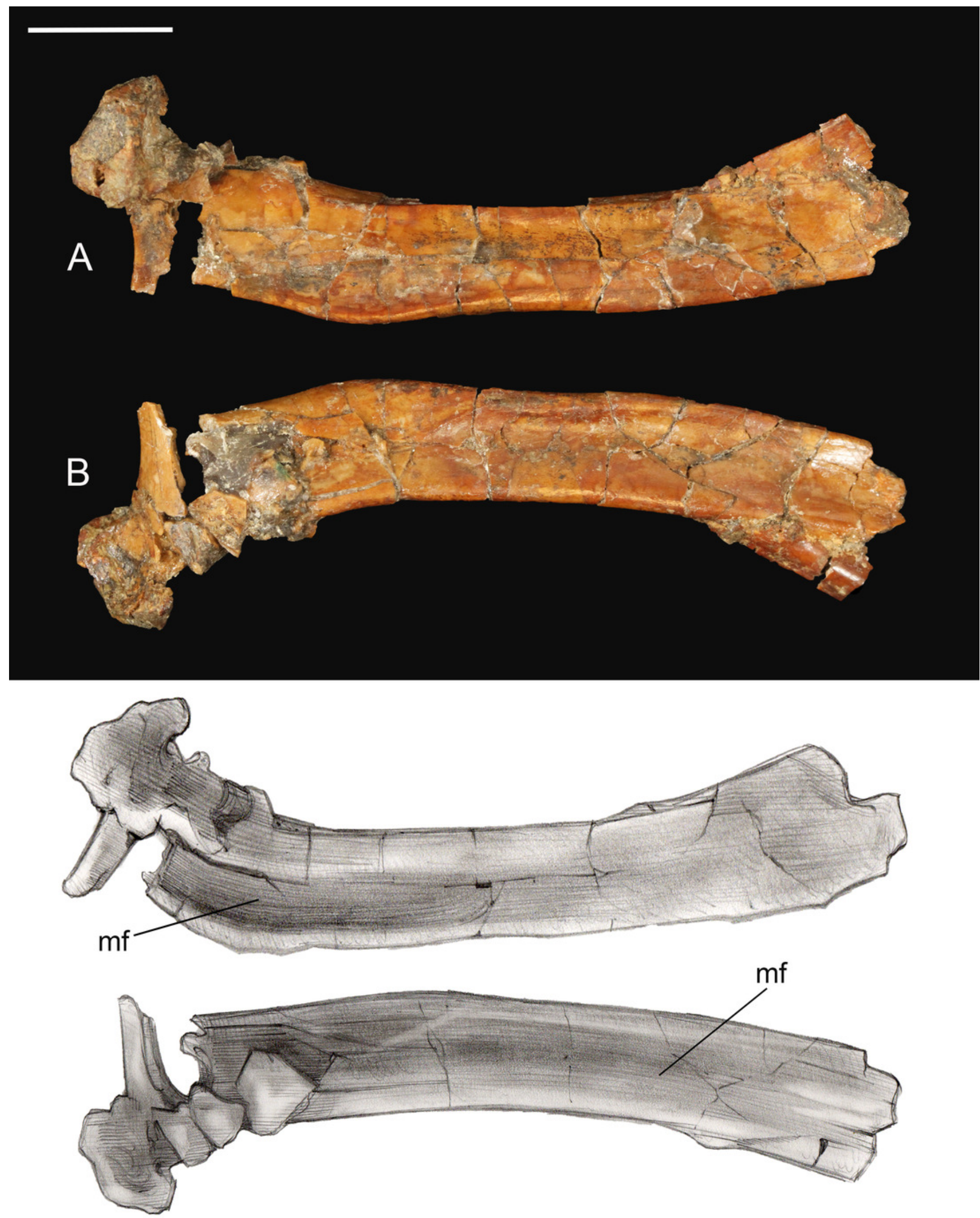


\section{Figure 7}

Partial left coracoid.

(A) Lateral view. (B) Medial view. (C)\&(E) Dorsal view. (D)\&(F) Ventral view. Abbreviations: apr, acoracoidal process; atu, acoracoidal tubercle; gf, glenoid facet; gr, medial groove; la, lateral angle; ma, medial angle; sc, scapula. Photos: David Strauss. Illustrations: Gregory C. Arena. 

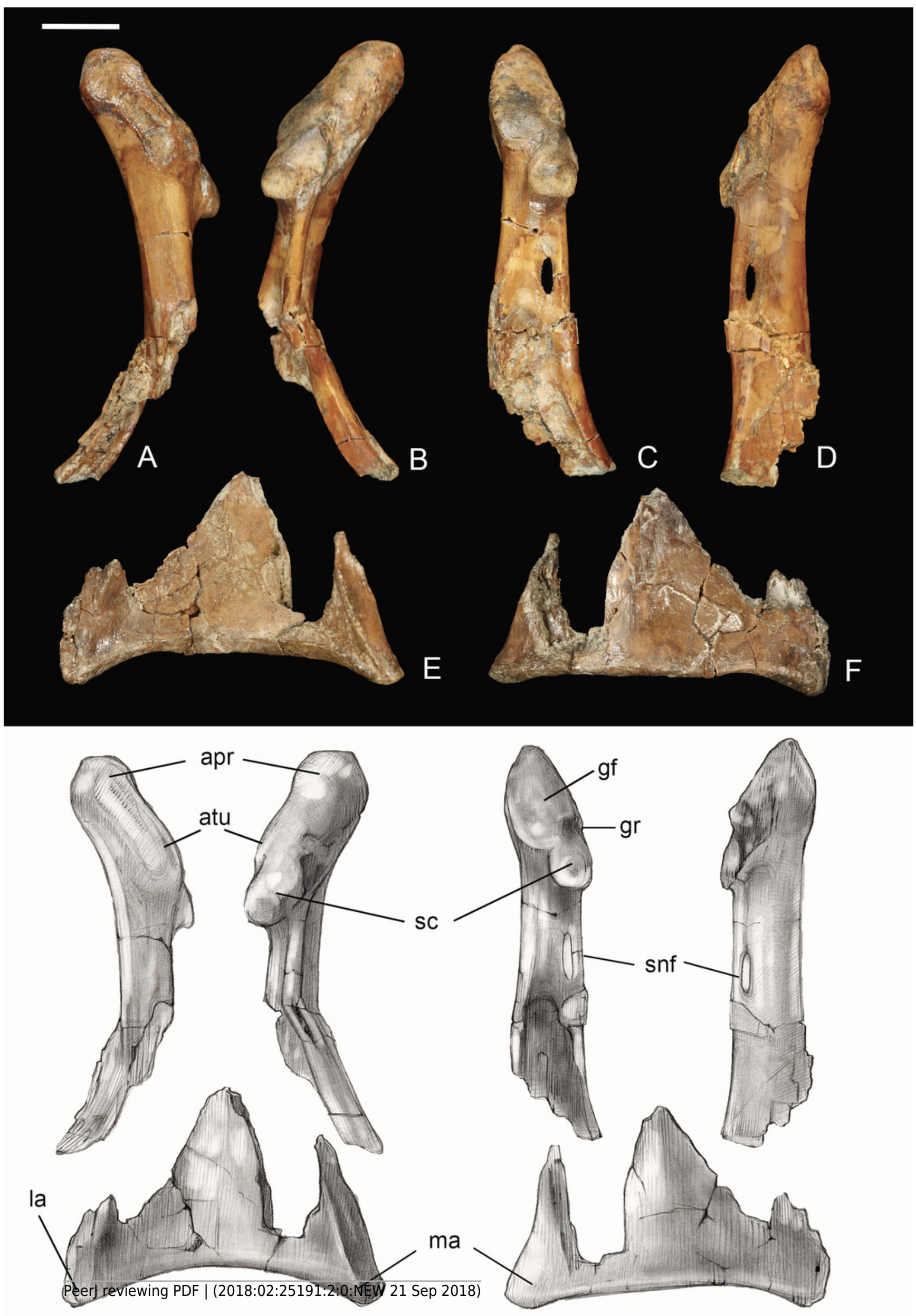


\section{Figure 8}

\section{Left humerus.}

(A) Cranial view. (B) Caudal view. (C) Lateral view. (D) Medial view. (E) Proximal view. (F)

Distal view. Abbreviations: bc, bicipetal crest; bf, brachialis fossa; cbi, coracobrachial impression; ci, capital incisure; dc, dorsal condyle; dpc, deltopectoral crest; fp, flexor process; hh, humeral head; ptf, pneumotricipital fossa; vc, ventral condyle. Scale bar equals 1cm. Photos: David Strauss. Illustrations: Gregory C. Arena. 

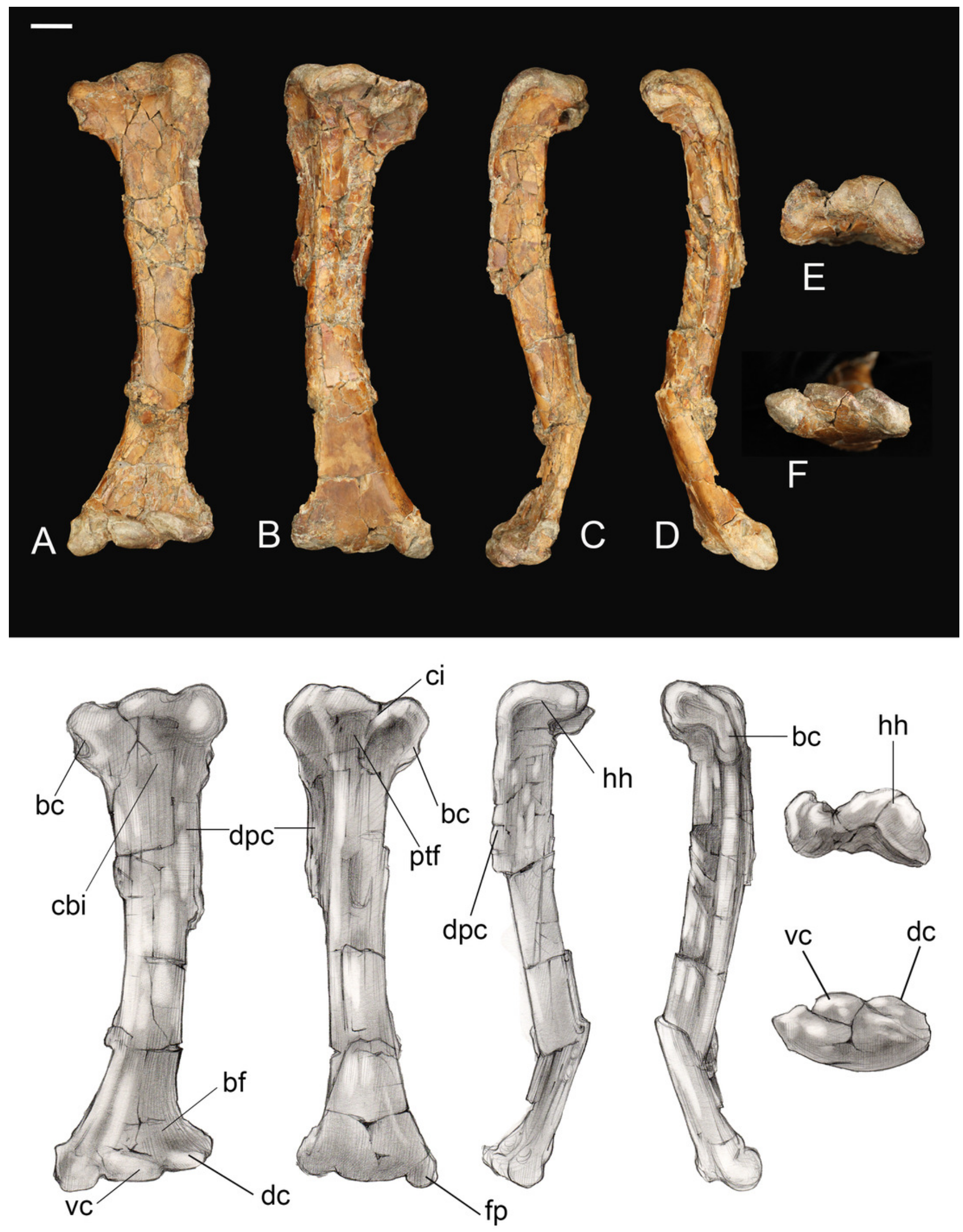


\section{Figure 9}

Quill knobs on Mirarce eatoni and Pelecanus occidentalis.

(A) Right ulna of Mirarce. (B) Close-up photo of the ulna of a modern Pelecanus. Abbreviation: qk, quill knobs. Scale bar equals $1 \mathrm{~cm}$. Photos: Dave Strauss.

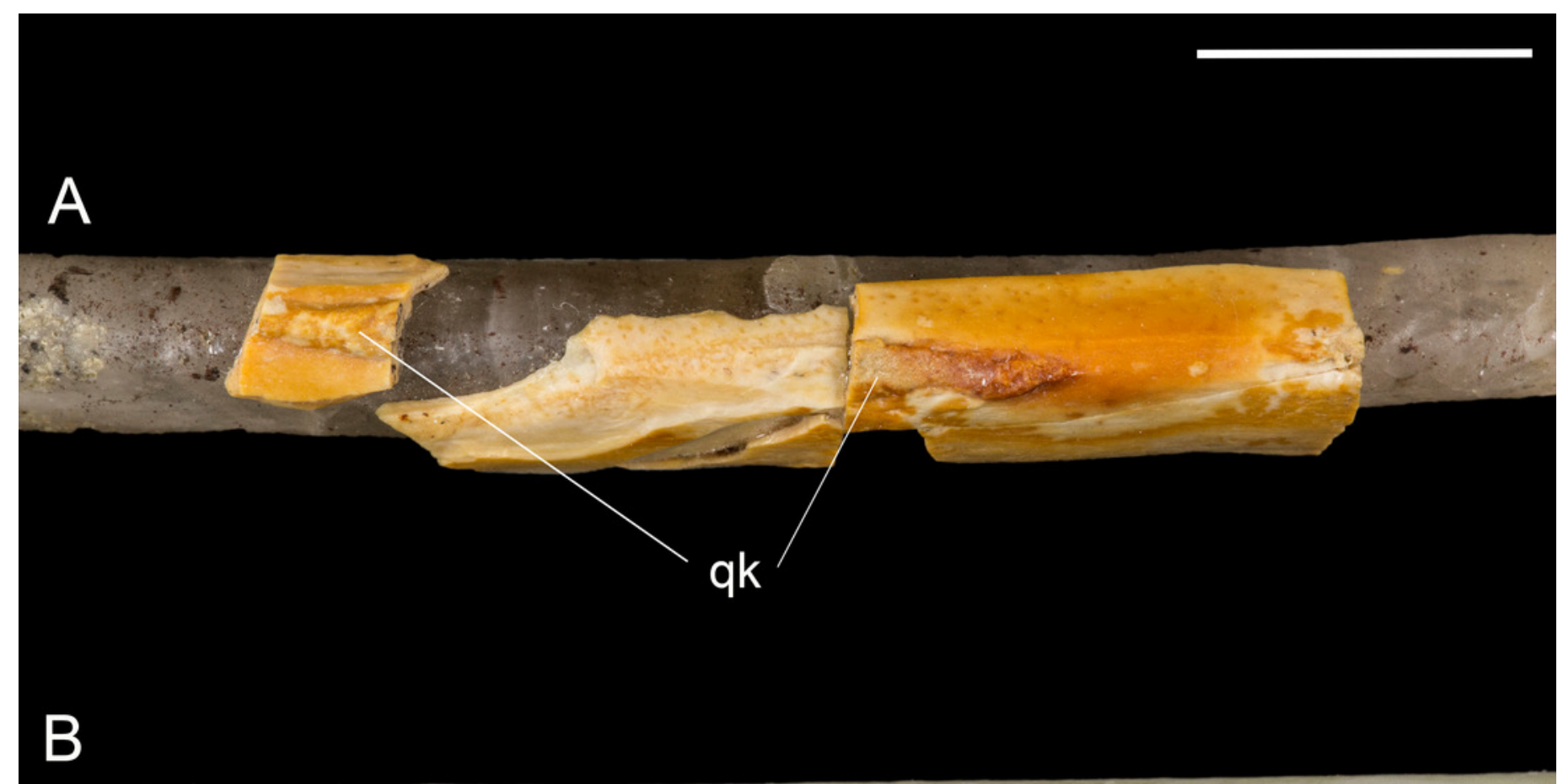




\section{Figure 10}

Identifiable preserved fragments of right manus.

(A) Carpometacarpus in lateral view. (B) Carpometacarpus in medial view. (C)

Carpometacarpus in ventral view. (D) Carpometacarpus in proximal view. (E) First phalanx of major digit in ventral view. (F) First phalanx of major digit in dorsal view. (G) First phalanx of major digit in lateral view. (H) First phalanx of major digit in medial view. Abbreviations: cat, carpal trochlea; crp, cranial pillar; uaf, ulnocarpal articular facet; vr, ventral ridge. Scale bar equals $1 \mathrm{~cm}$. Photos: David Strauss.

*Note: Auto Gamma Correction was used for the image. This only affects the reviewing manuscript. See original source image if needed for review. 


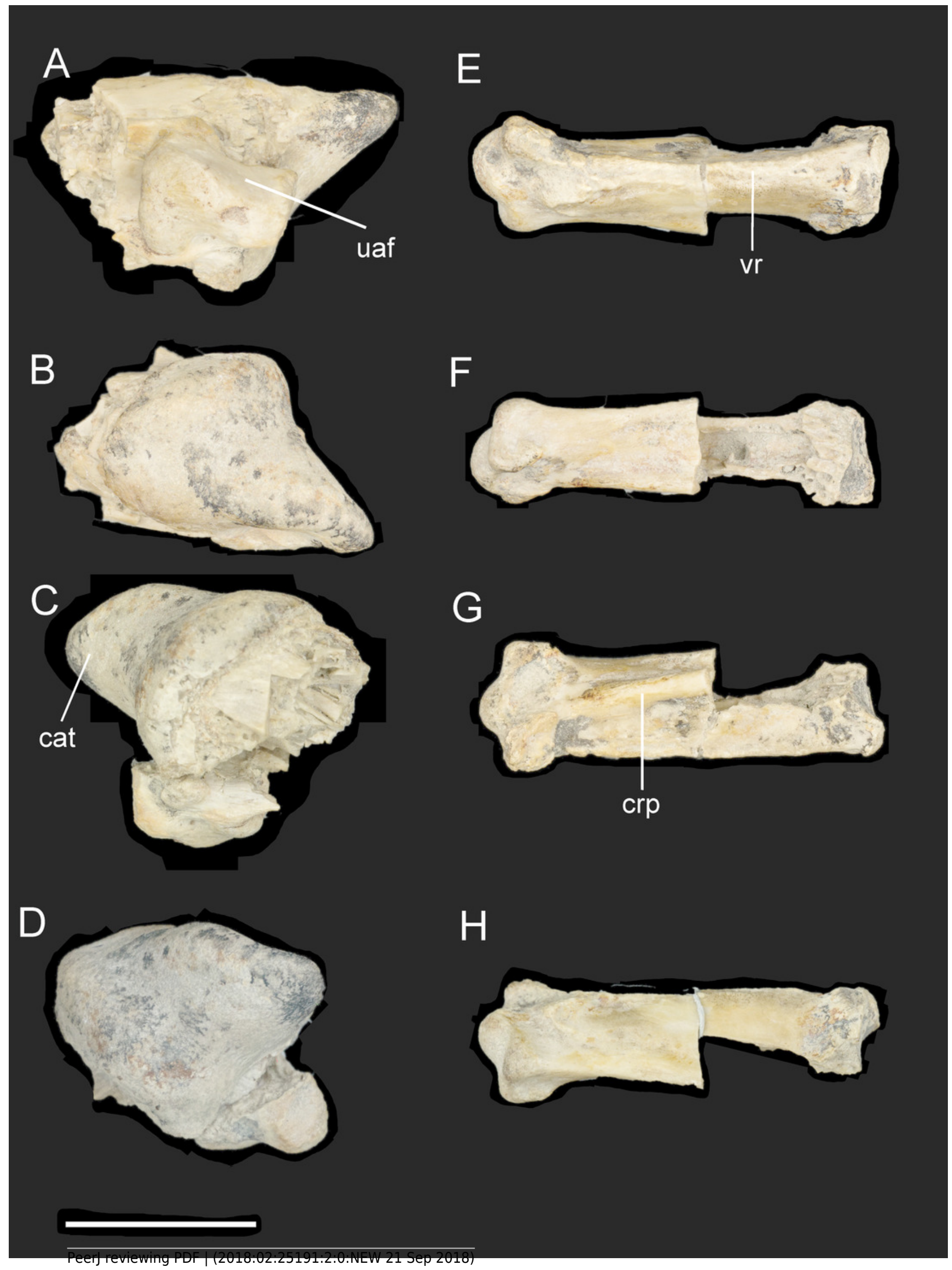




\section{Figure 11}

Pelvic girdle fragment.

(A) Lateral view. (B) Medial view. Abbreviations: ace, acetabulum; ant, antitrochanter; dat, dorsal antitrochanter; ili, ilium; isc, ischium; pub, pubis; sac, supracetabular crest. Scale bar equals $1 \mathrm{~cm}$. Photos: David Strauss. Illustrations: Gregory C. Arena. 

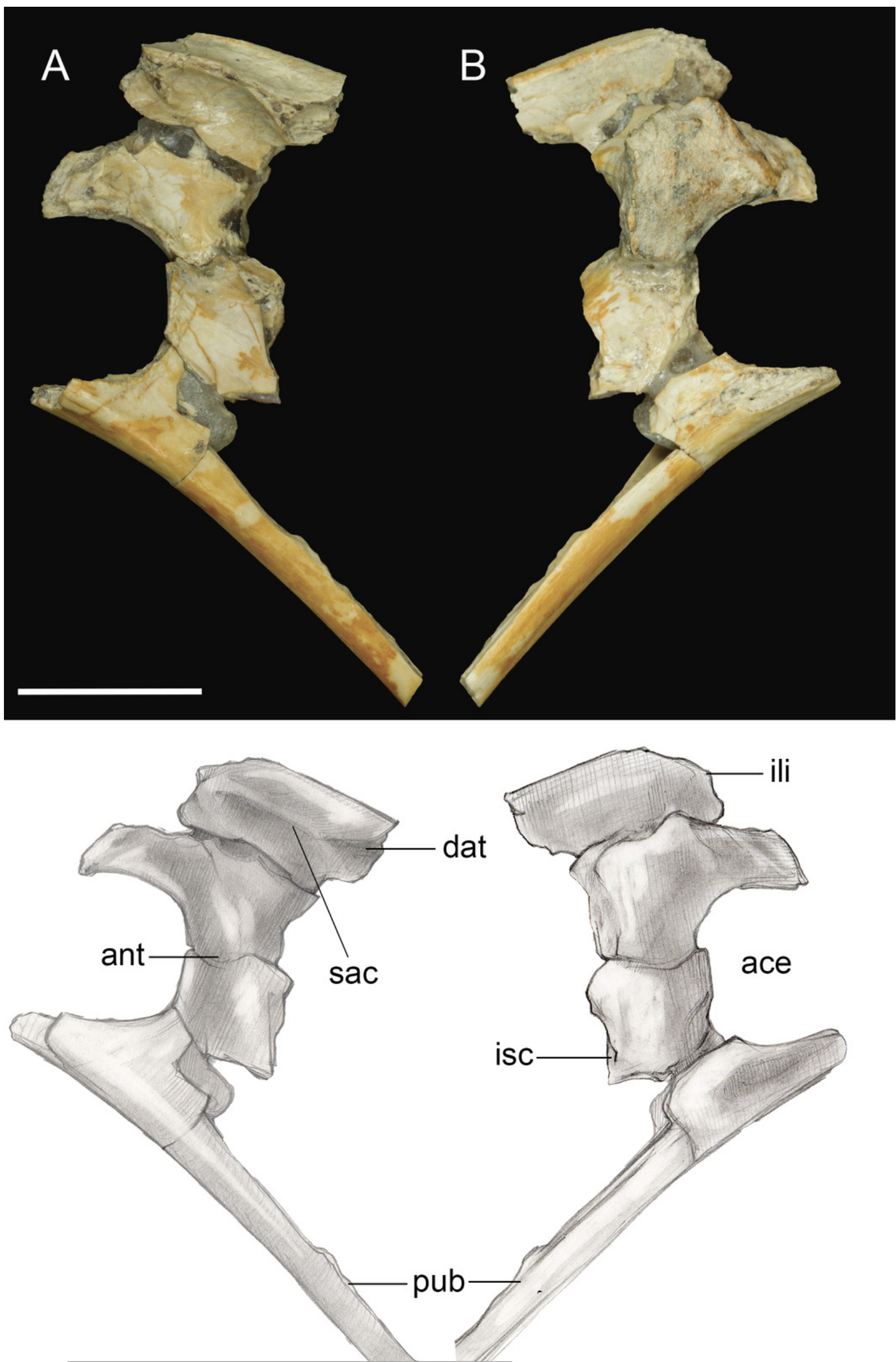


\section{Figure 12}

Right femur.

(A) Cranial view. (B) Caudal view. (C) Medial view. (D) Lateral view. (E) Proximal view. (F)

Distal view. Abbreviations: cil, cranial intermuscular line intermuscular line; Ic, lateral condyle; Igt, lateral gastrocnemial tubercle; lil, lateral intermuscular line; iicm, insertion of $m$. iliotrochantericus cranialis and medius; $\mathrm{mc}$, medial condyle; ofm, origin of $m$. femorotibialis medialis; pt, posterior trochanter. Scale bar equals $1 \mathrm{~cm}$. Photos: David Strauss. Illustrations: Gregory C. Arena. 

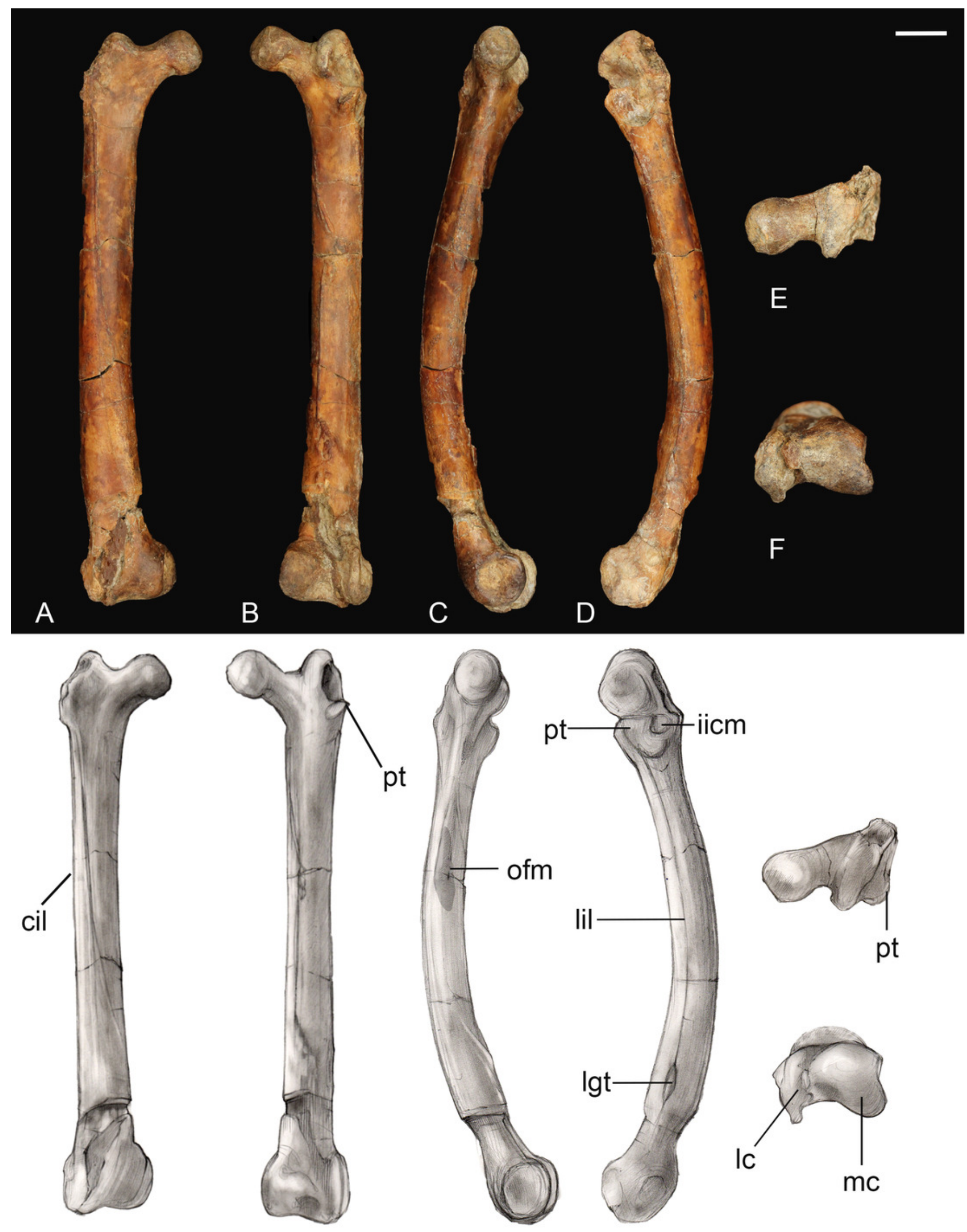


\section{Figure 13}

Preserved fragments of right tibiotarsus.

(A) Proximal view. (B) Lateral view. (C) Cranial views. Abbreviations: dt, distal tubercle; Ic, lateral condyle; Ite, lateral trochlear excavation; mc, medial condyle; pt, proximal tubercle. Scale bar equals $1 \mathrm{~cm}$. Photos: David Strauss. Illustrations: Gregory C. Arena. 

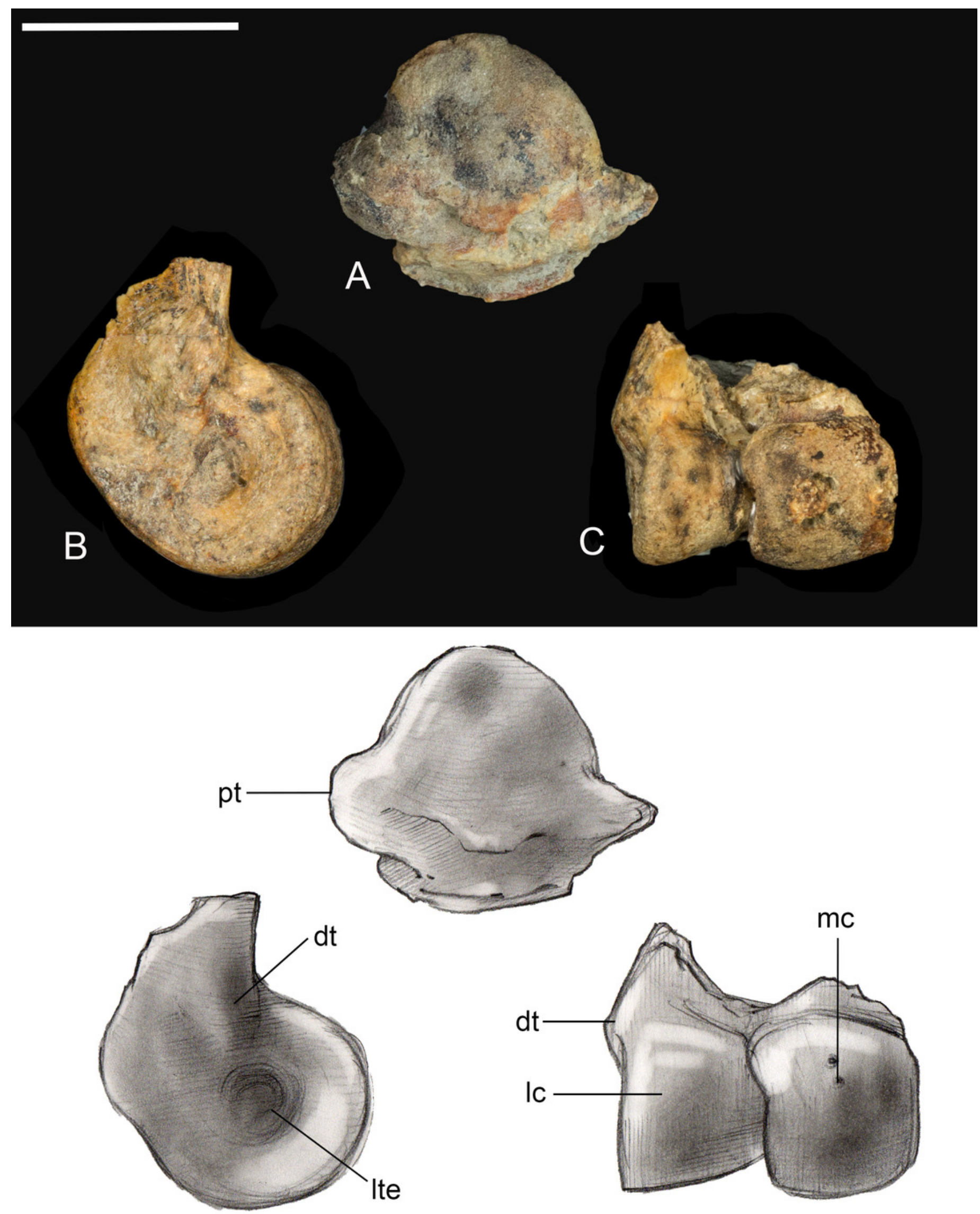


\section{Figure 14}

\section{Left tarsometatarsus.}

(A) Dorsal view. (B) Plantar view. (C) Medial view. (D) Lateral. (E) Proximal view. (F) Distal view. Abbreviations: Ic, lateral cotyle; mc, medial cotyle; mtla?, metatarsal I articulation?; mtII, metatarsal II; mtIII, metatarsal III; mtIV, metatarsal IV; pl, proximal labum; std, supratrochlear depression; tct, tibialis cranialis tubercle. Scale bar equals $1 \mathrm{~cm}$. Photos: David Strauss. Illustrations: Gregory C. Arena. 

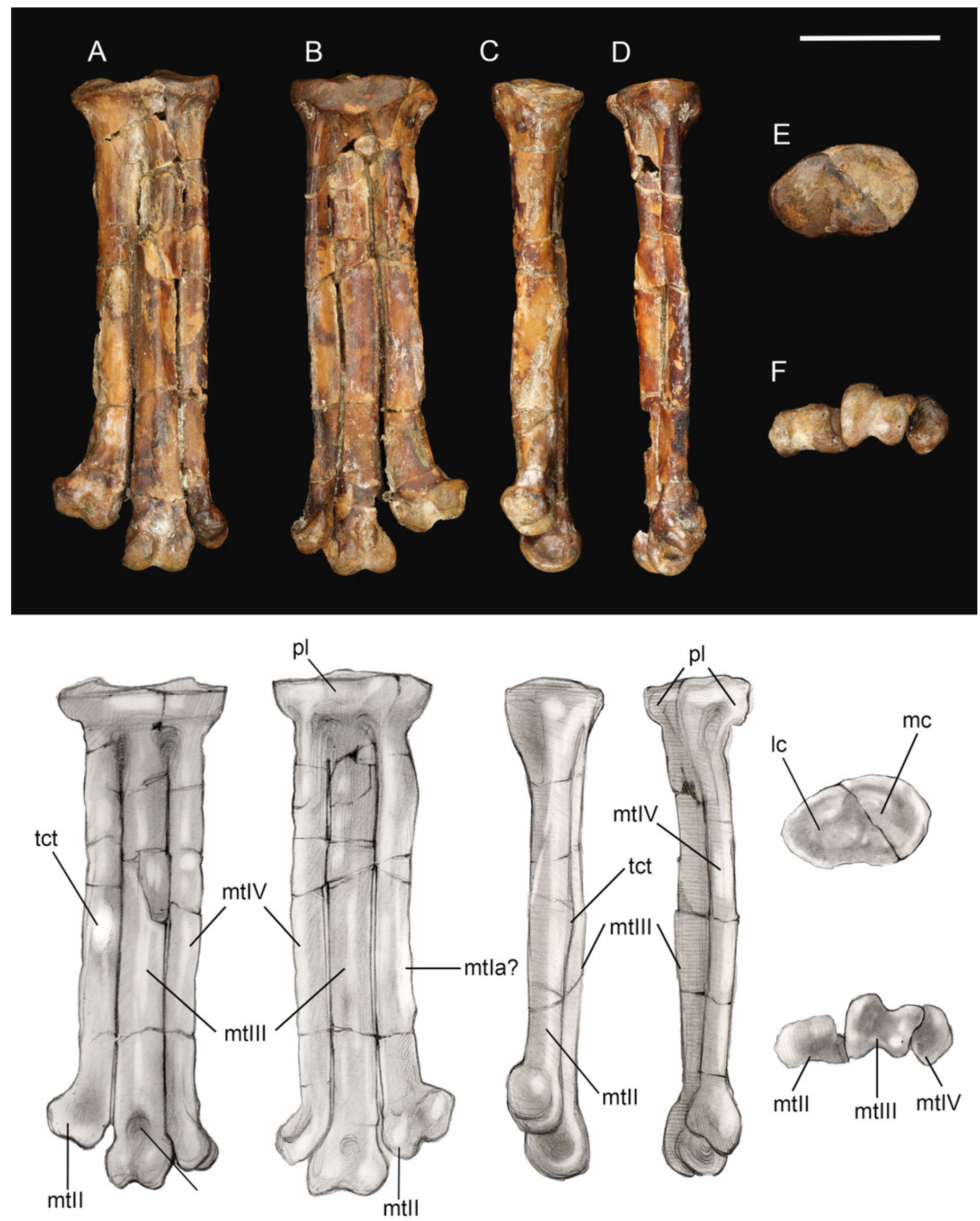


\section{Figure 15}

Comparison of avisaurid tarsometatarsi showing variation in size of the element and location of the tibialis cranialis tubercle, among other morphological variations.

(A) Avisaurus archibaldi. (B) Mirarce eatoni. (C) Gettyia gloriae. (D) Bauxitornis

mindszentyae. (E) Sauroavisaurus australis. Abbreviations: tct, tibialis cranialis tubercle.

Scale bar equals $1 \mathrm{~cm}$. Illustrations: Gregory C. Arena. 


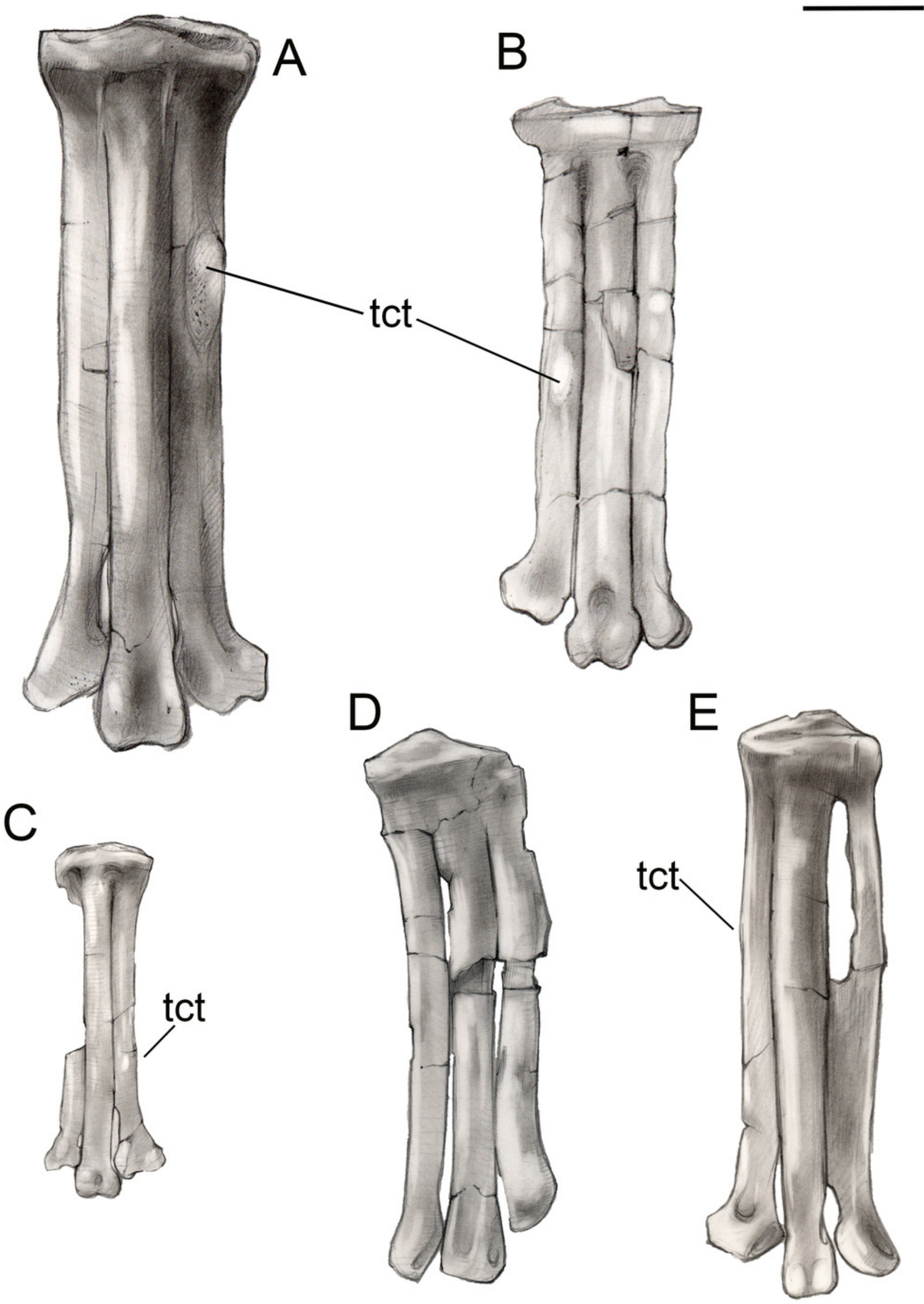




\section{Figure 16}

Non-ungual pedal phalanges of the left foot.

(A) Proximal view. (B) Distal view. (C) Dorsal view. (D) Medial view. Elements are identified on the left by digit number and phalanx number (D\#,P\#). Scale bar equals $0.5 \mathrm{~cm}$. Photos: David Strauss.

*Note: Auto Gamma Correction was used for the image. This only affects the reviewing manuscript. See original source image if needed for review. 


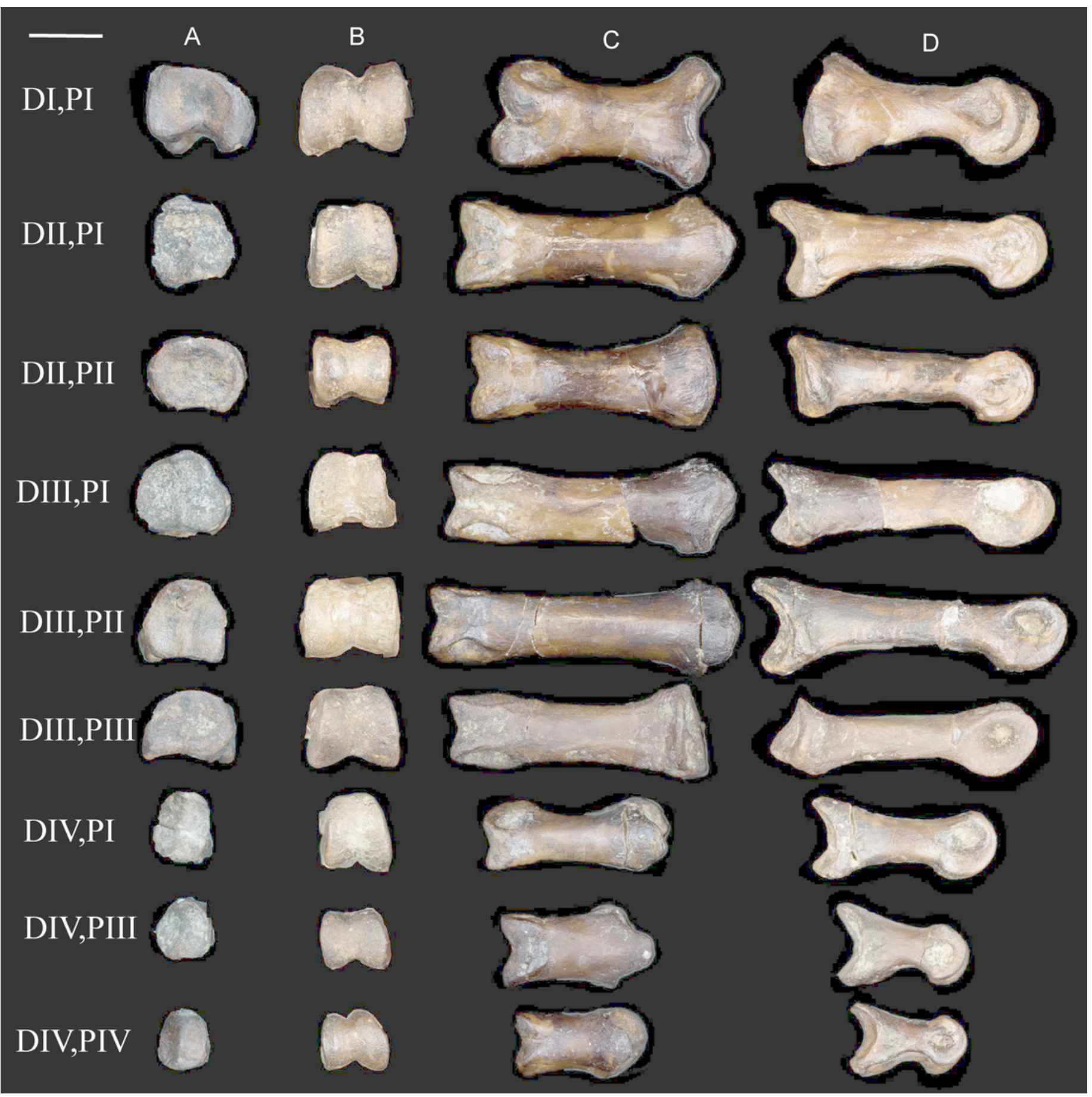




\section{Figure 17}

Ungual pedal phalanges of the left foot.

(A) Proximal. (B) Lateral view. Digit number is identified on the left. Scale bar equals $0.5 \mathrm{~cm}$.

Photos: David Strauss.

*Note: Auto Gamma Correction was used for the image. This only affects the reviewing manuscript. See original source image if needed for review. 


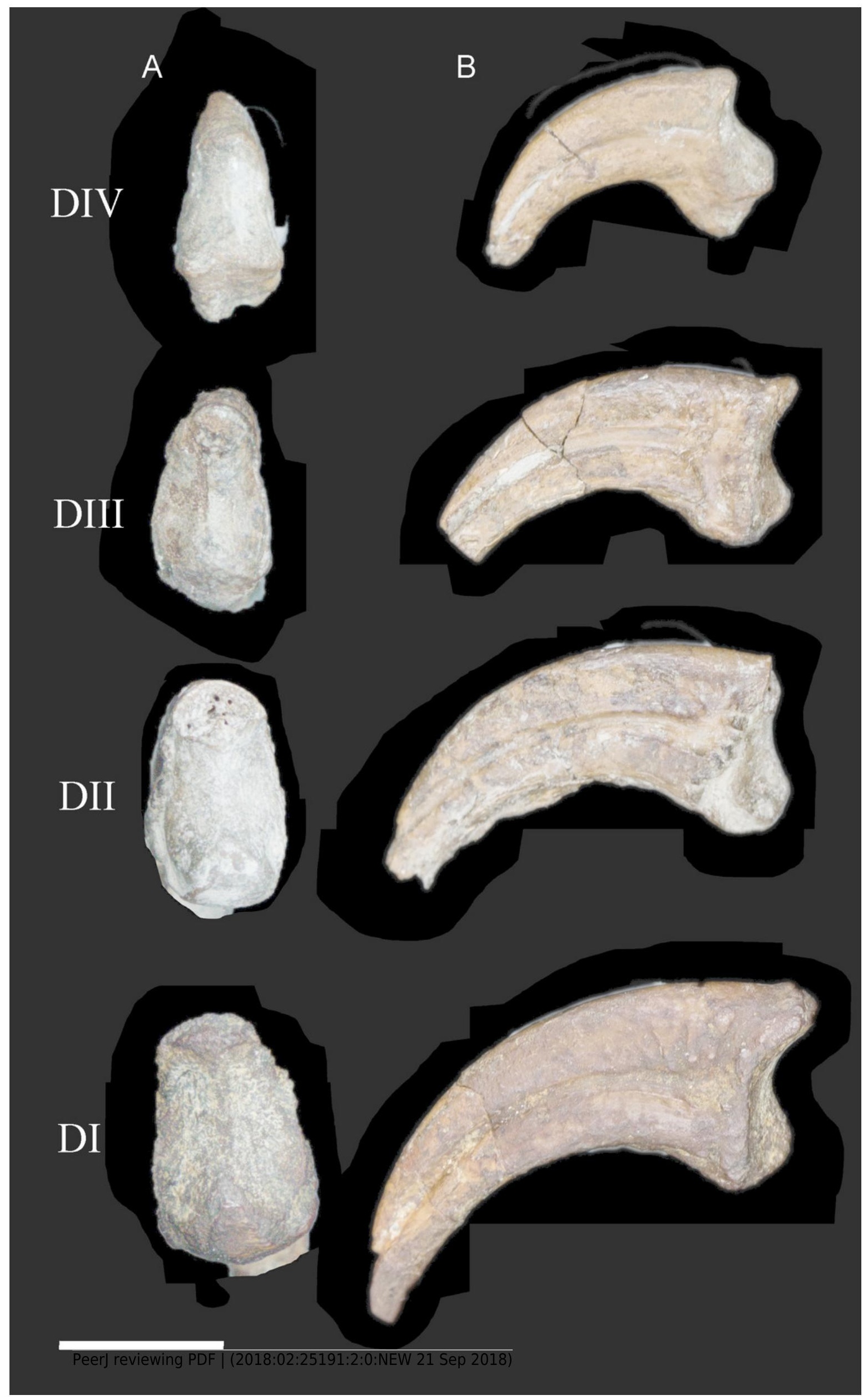




\section{Figure 18}

A cladogram depicting the hypothetical phylogenetic position of Mirarce eatoni.

This is the strict consensus tree (Consistency Index $=0.453$; Retention Index $=0.650$ ) produced from six most parsimonious trees (score of 25.1; $\mathrm{k}$ value of 13 ). These six trees differed only in the relative placement of the five enantiornithines most closely related to the Avisauridae, which here form a polytomy with this clade. 


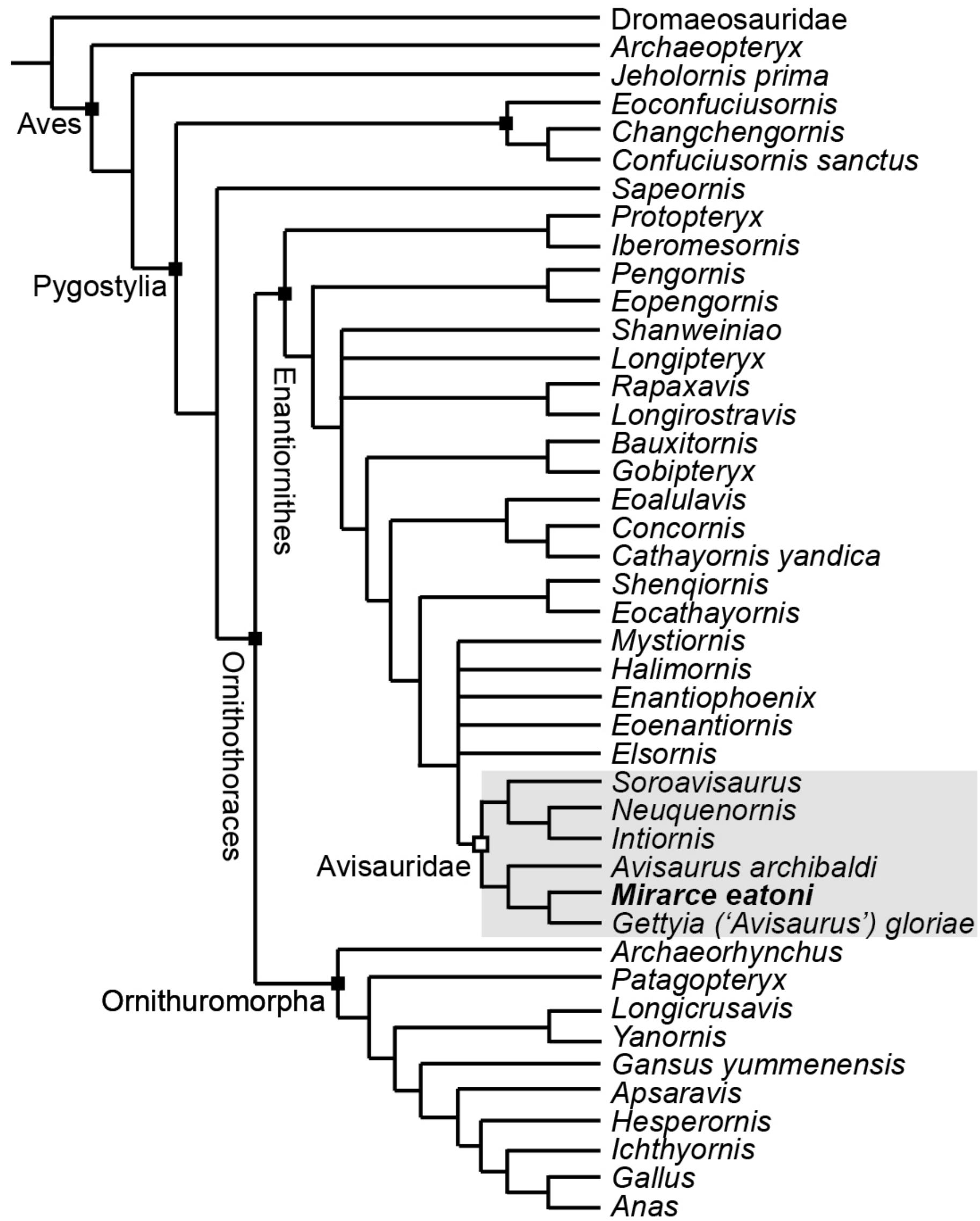




\section{Figure 19}

A skeletal reconstruction of Mirarce eatoni showing preserved skeletal elements (white).

Illustration: Scott Hartman.

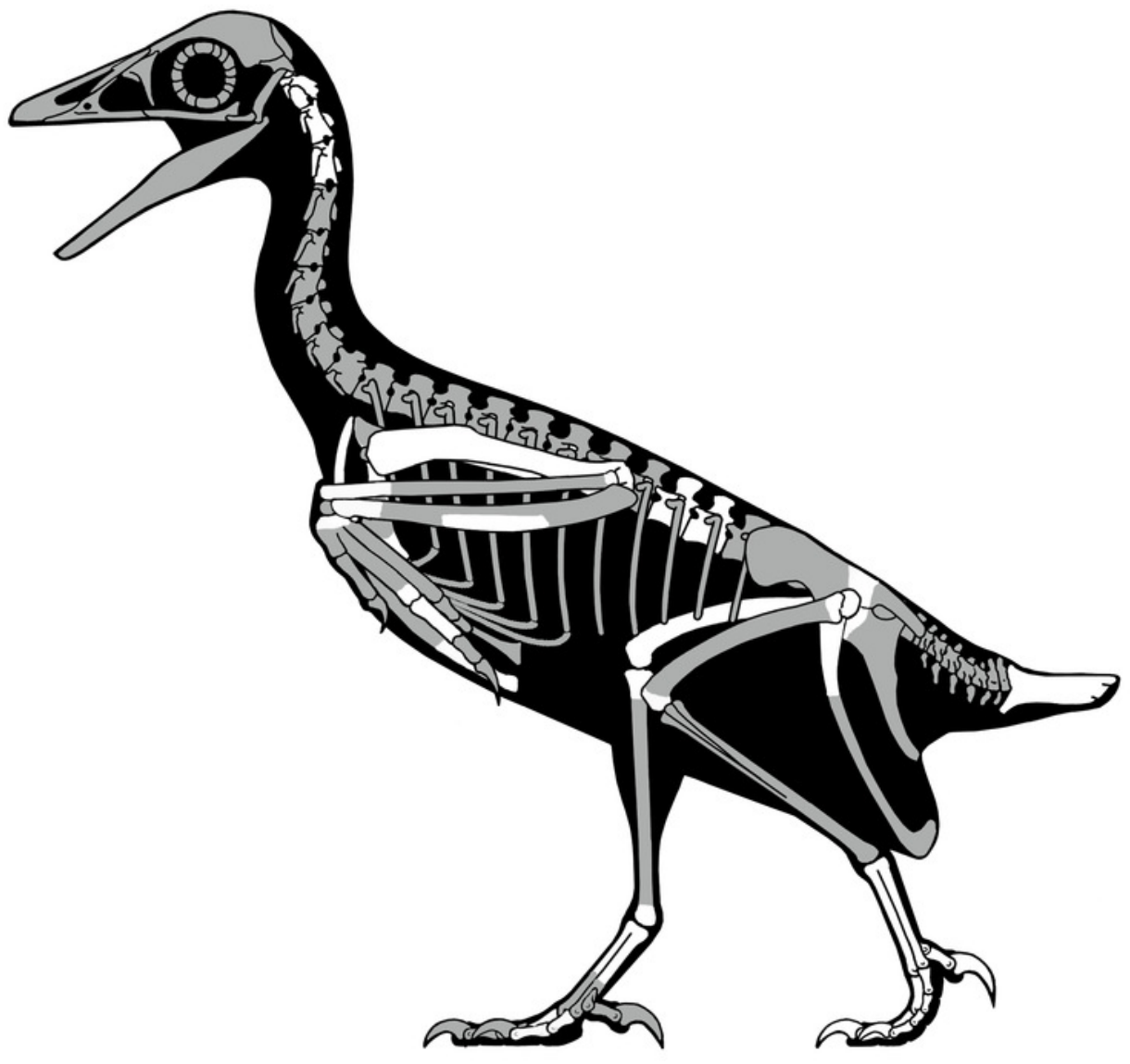




\section{Figure 20}

A reconstruction of living Mirarce eatoni, illustrating the large body size of this taxon.

Illustration: Brian Engh.

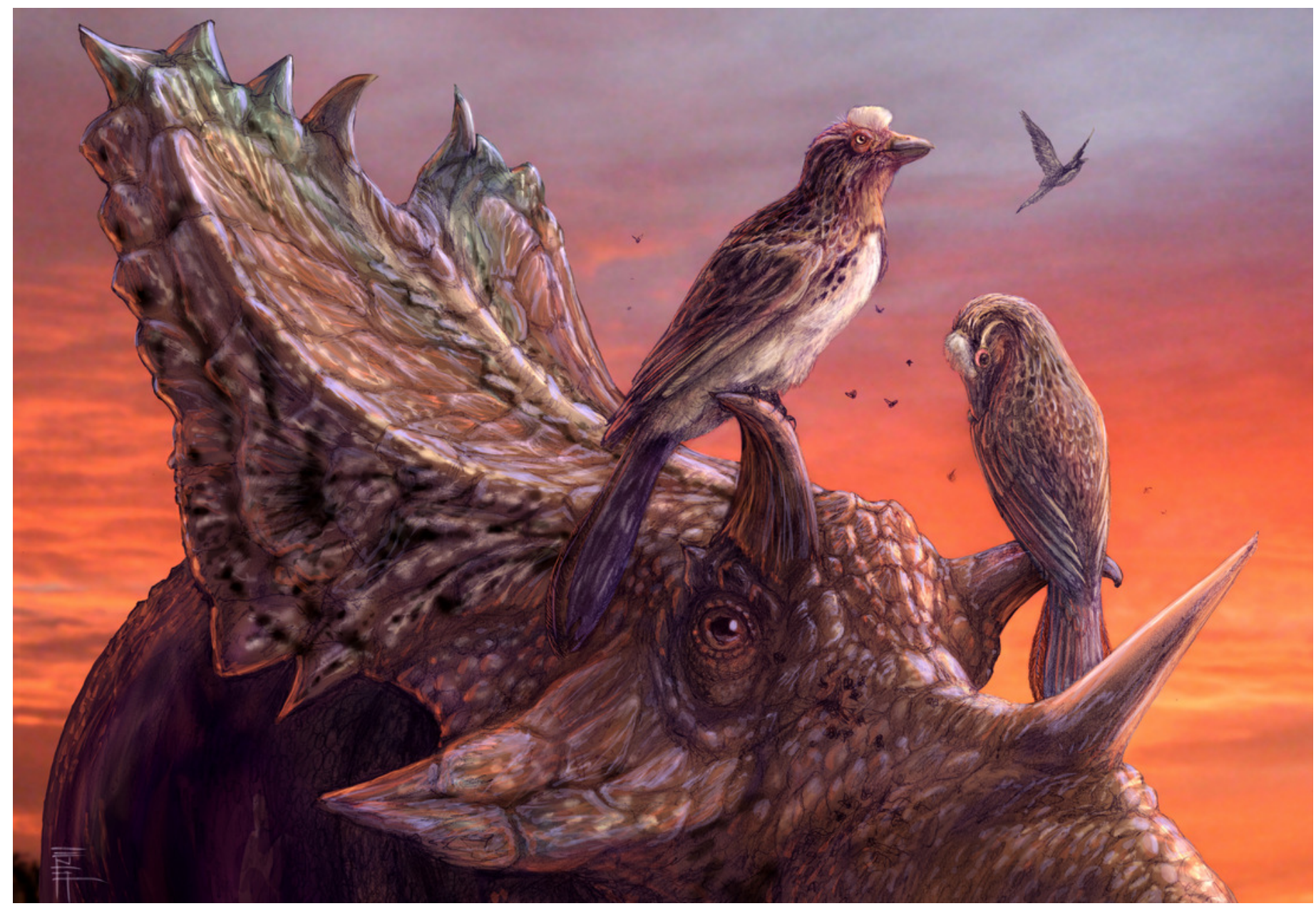

